\title{
Arsênio do minério de manganês de Serra do Navio
}

Wilson Scarpelli - Graduado em Geologia na Universidade de São Paulo - USP. Mestrado em Stanford University, EUA e Tem mais de 30 anos de experiência pelas atividades executadas na ICOMI.

\section{Resumo}

Este texto trata-se da exposição ao arsênio (As) através de resíduos da exploração de manganês (Mn) desenvolvida pela ICOMI. A avaliação do meio físico no estudo sobre o arsênio no Estado do Amapá precedeu o estudo de saúde humana porque era necessário conhecer as fontes e rotas de exposição que pudessem estar atingindo as comunidades humanas. Dentre as várias vias de exposição ao arsênio, a água de consumo representa o maior risco para a saúde humana. Devido à divulgação da contaminação por arsênio na Área Industrial e de teores anômalos no Igarapé. Foi realizado um trabalho detalhado de amostragem de águas do Canal Norte do Rio Amazonas a partir de Santana até próxima do mar analisandoas para arsênio, com o trabalho sendo repetido ao longo do Rio Pará, do canal de Breves até a sua foz. A afinidade química entre o manganês e arsênio é tão boa, ou até melhor que a afinidade por ferro. O minério óxido da Serra do Navio é um bom exemplo disso. A afinidade tem sido usada técnica e comercialmente na produção de equipamentos para remoção de arsênio de água com a finalidade de torná-la potável.

\section{Palavras-chave}

Arsênio, intemperismo, contaminação, Eslebão e Área Industrial.

\section{Abstract}

This text it is the exposition of arsenic (As) through residous of manganese $(\mathrm{Mn})$ exploration developed by ICOMI. The avaliation of the phisical emvironment in the study on the arsenic in the State of Amapá anticipated the sudy of human health once was necessary to know the sources and routes of exposition which could be reaching the human comunities. Among the several arsenic exposition ways, the consumption of water presents the greatest risc concerning the human health. Due to the divulgation of arsenic in the Industrial Area and anomalous grades in rivers. A work had been detailed on the water samples of the North Channel of the Amazon River from Santana, close to the sea analysing the arsenic and been repeated along of Pará River, from Breves Chanel to its mouth. The chemical affinity between mangnese and arsenic is good and much better than affinity by the iron. The Serra do Navio oxide ore is a good example. The affinity has been a technique used and comercially in the equipments production for arsenic in removing water in order to become potable.

\section{Keywords}

Arsenic, weathering, contamination, Eslebão, Industrial Area. 


\section{INTRODUÇÃO}

A Serra do Navio situa-se no Amapá, a aproximadamente $0{ }^{\circ} 55^{\prime}$ norte e $52^{\circ} 05^{\prime}$ oeste, às margens do rio Amapari, o qual faz parte da bacia hidrográfica do rio Araguari, que corre diretamente para o mar. O minério de manganês ali produzido foi escoado por $192 \mathrm{~km}$ por estrada de ferro, até o porto de Santana, situado à margem esquerda do canal norte do rio Amazonas.

\section{GEOLOGIA E ORIGEM DOS MINÉRIOS}

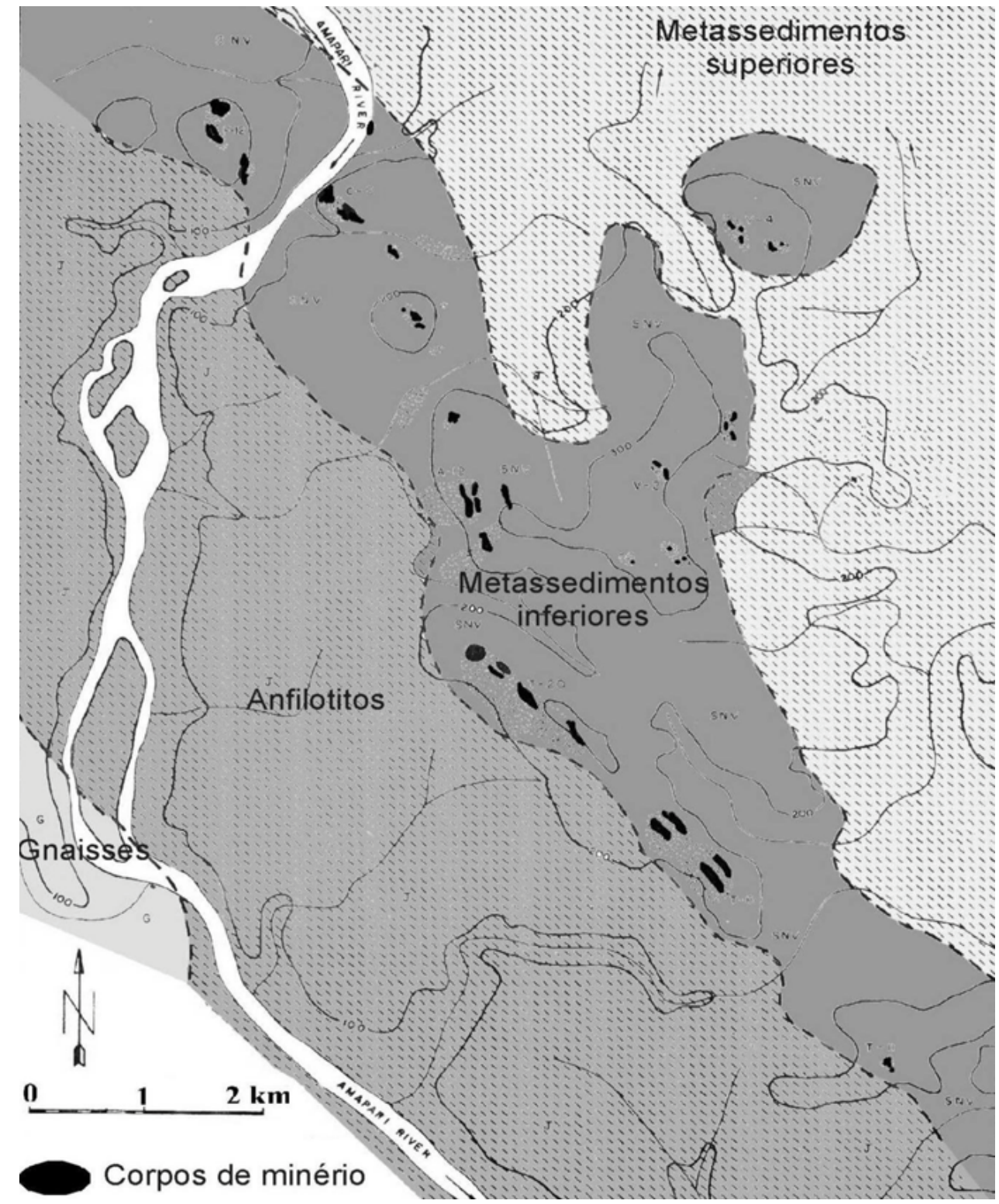

Figura 1: Mapa geológico de Serra do Navio, mostrando o posicionamento dos afloramentos do minério manganesífero em cristas topográficas. 
As rochas de Serra do Navio têm idade pré-cambriana, com aproximadamente 1,8 bilhões de anos (Figura 1). Ali ocorrem gnaisses e granitos, lavas máficas metamorfizadas em anfibolito e duas unidades de sedimentos finos a químicos, metamorfizadas em xistos e mármores. $\mathrm{Na}$ unidade inferior de sedimentos há níveis de mármores manganesíferos.

Devido à pluviosidade, às altas temperaturas e à acidez das águas, essas rochas estão intensamente decompostas, com a alteração chegando a mais de $100 \mathrm{~m}$ de profundidade (Figura 2). Nessas condições, durante a alteração, muitos elementos químicos das rochas, como o potássio, o sódio, o cálcio e outros, são removidos com a água de subsolo. Outros elementos, como o ferro, o alumínio e o manganês, após dissolução inicial, permanecem em forma solúvel ou formam colóides e cristalizam-se ou consolidam-se como óxidos e hidróxidos, em um processo que chega a formar, respectivamente, carapaças de laterita, de bauxita e de minério de manganês. Vários elementos, como o arsênio e o cobalto, são retidos e concentram-se nos óxidos e hidróxidos de ferro e de manganês.

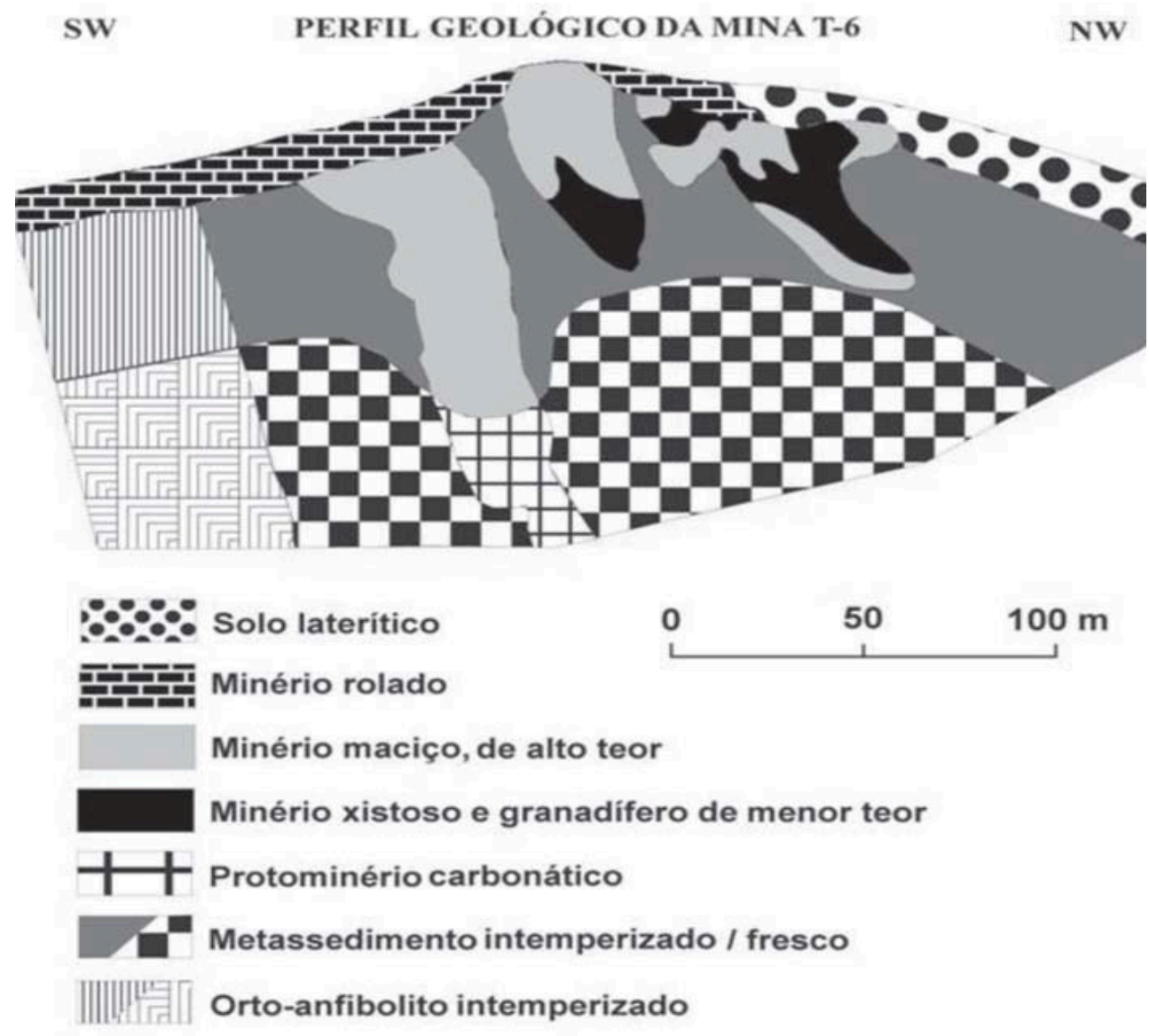

Figura 2: Perfil geológico da mina T-6, mostrando a intensa intemperização e o aparecimento dos minérios óxidos tomando os lugares dos protominérios. 


\section{TIPOS DE MINÉRIOS E A PRESENÇA DE ARSÊNIO}

Há dois tipos de minério na Serra do Navio, ambos mostrados na Figura 2: um primário, ou inicial, formado pelas camadas do mármore manganesífero, e um secundário, ou óxido, formado por massas de óxidos e hidróxidos de manganês.

O minério carbonático ocorre em profundidade, abaixo do nível de água freático, e contém carbonato (rodocrosita) e silicatos (espessartita e tefroíta) de manganês, mais quantidades traço de sulfetos de zinco, de cobalto e de níquel. Possui de 20 a 32\% de manganês. Os xistos adjacentes aos mármores contêm quantidades traço de sulfetos de ferro e de cobre, os quais possuem concentrações traço de arsênio. Em nenhuma dessas rochas foi visto o mineral arsenopirita, que é o mineral mais comum de arsênio em depósitos ricos em sulfetos.

O minério óxido é formado pela intemperização dos mármores manganesíferos, em um processo que ocorre hoje. Quando a rocha é decomposta e a maioria dos demais elementos é removida em solução, o manganês é oxidado pelas águas pluviais e hidrolisado e, freqüentemente passando por uma fase coloidal, depositado como óxidos e hidróxidos nos espaços ocupados anteriormente pelos carbonatos e silicatos. Os teores resultantes variam de 32 a 52\% de manganês.

O minério óxido é constituído de minerais manganesíferos como pirolusita (óxido), psilomelana (hidróxido de manganês e bário), litioforita (hidróxido de manganês), associados a quantidades menores de limonita (óxido de ferro), goethita (hidróxido de ferro), gibbsita (óxido de alumínio), argilas, sílica e outros minerais secundários. O arsênio derivado das rochas próximas aos mármores fica retido na estrutura cristalina dos óxidos e hidróxidos de ferro e de manganês.

Como se formaram nas condições ambientais atuais, os minerais do minério óxido são muito estáveis, e o arsênio neles contidos não é liberado em condições normais. Há, inclusive, boa relação entre os teores de manganês e de arsênio, com o minério de 48\% de manganês sempre contendo entre 0,17 e 0,18\% de arsênio.

\section{HISTÓRIA DA PRODUÇÃO}

A Indústria e Comércio de Minérios S/A (ICOMI) lavrou e comercializou minérios de manganês da Serra do Navio de 1957 a 1997. A maior parte da produção foi constituída de blocos naturais de minério, os quais, no processo de preparo para a venda, não sofreram nenhuma alteração química ou mineral em sua constituição. Foram apenas britados, peneirados e classificados granulometricamente, até atingirem as especificações exigidas pelos compradores, e lavados, para a remoção de argilas. 
Até meados dos anos 70, os fragmentos mais finos, menores que um milímetro, não encontravam compradores e eram estocados na Serra do Navio. Para a comercialização desses finos, foi construída, perto do porto, uma usina de pelotização, a qual, usando temperaturas da ordem de 900 a $1.000^{\circ} \mathrm{C}$, aglomerava os finos em pelotas endurecidas de cerca de um centímetro de diâmetro, o que permitia sua venda. A usina operou de 1973 a 1983, interrompendo a produção de pelotas quando o mercado consumidor passou a solicitar o fino em estado natural e os preços dos combustíveis tornaram-se excessivamente altos. De 1989 até 1996 a usina foi usada para a produção de sínter, que é um aglomerado mais frágil que a pelota, formado a temperaturas da ordem de $700{ }^{\circ} \mathrm{C}$.

\section{O ARSÊNIO E A USINA DE PELOTIZAÇÃO}

Quando o minério fino foi aquecido a temperatura entre 900 e $1.000{ }^{\circ} \mathrm{C}$ para a produção de pelotas, parte do minério recristalizou-se em hausmanita e tefroíta, minerais instáveis à superfície. Parte do arsênio saiu da proteção dos hidróxidos de ferro e de manganês e tornouse solubilizável em condições ambientais. O arsênio solubilizável que ficou, porém, retido no interior das pelotas manteve-se estável, visto que ali não poderia ser alcançado. Todas as pelotas foram comercializadas e consumidas em altos-fornos, onde o arsênio foi removido por técnicas siderúrgicas convencionais.

No entanto, o processo de pelotização deixou uma quantidade de rejeitos, compostos de resíduos finos e algumas pelotas malformadas, mal compactadas ou pequenas. Esses rejeitos foram depositados em uma barragem artificial, situada ao lado da usina de pelotização (Figuras 1 e 2). A barragem constituía-se de uma escavação que alcançou o nível freático e era limitada lateralmente por um muro de terra compactada. Era dividida em duas metades por uma parede vertical. Na parte sul, foi depositado o rejeito magnético e, ao norte, o rejeito apenas fino, não magnético.

Ali o arsênio solubilizável à superfície dos grãos foi dissolvido e contaminou a água da barragem e as águas de subsolo em suas imediações. Quando a contaminação foi identificada, o rejeito foi retirado da barragem, depositado em terra firme e coberto por plástico. Foi dimensionado ao ser removido da barragem, chegando a 75.600 toneladas.

Essa remoção foi executada em 1998. Durante a operação, foi verificado que o rejeito continha grande quantidade de material coloidal, formado no próprio local a partir de minerais como a hausmanita e a tefroíta. Ao ser retirado, "o rejeito tinha uma capa oxidada sólida com razoável capacidade de suporte, abaixo desta capa o material formava um colóide muito mole e liquefeito com alto teor em água. Esta característica dificultou o manuseio deste durante a retirada" (HIDRO AMBIENTE PROJETOS, CONSULTORIA E SERVIÇOS S/C, 1999). 
Quanto à água da barragem após a retirada dos rejeitos, o arsênio nela contido oxida-se natural e constantemente, precipitando-se juntamente com hidróxidos de ferro e de manganês neoformados.

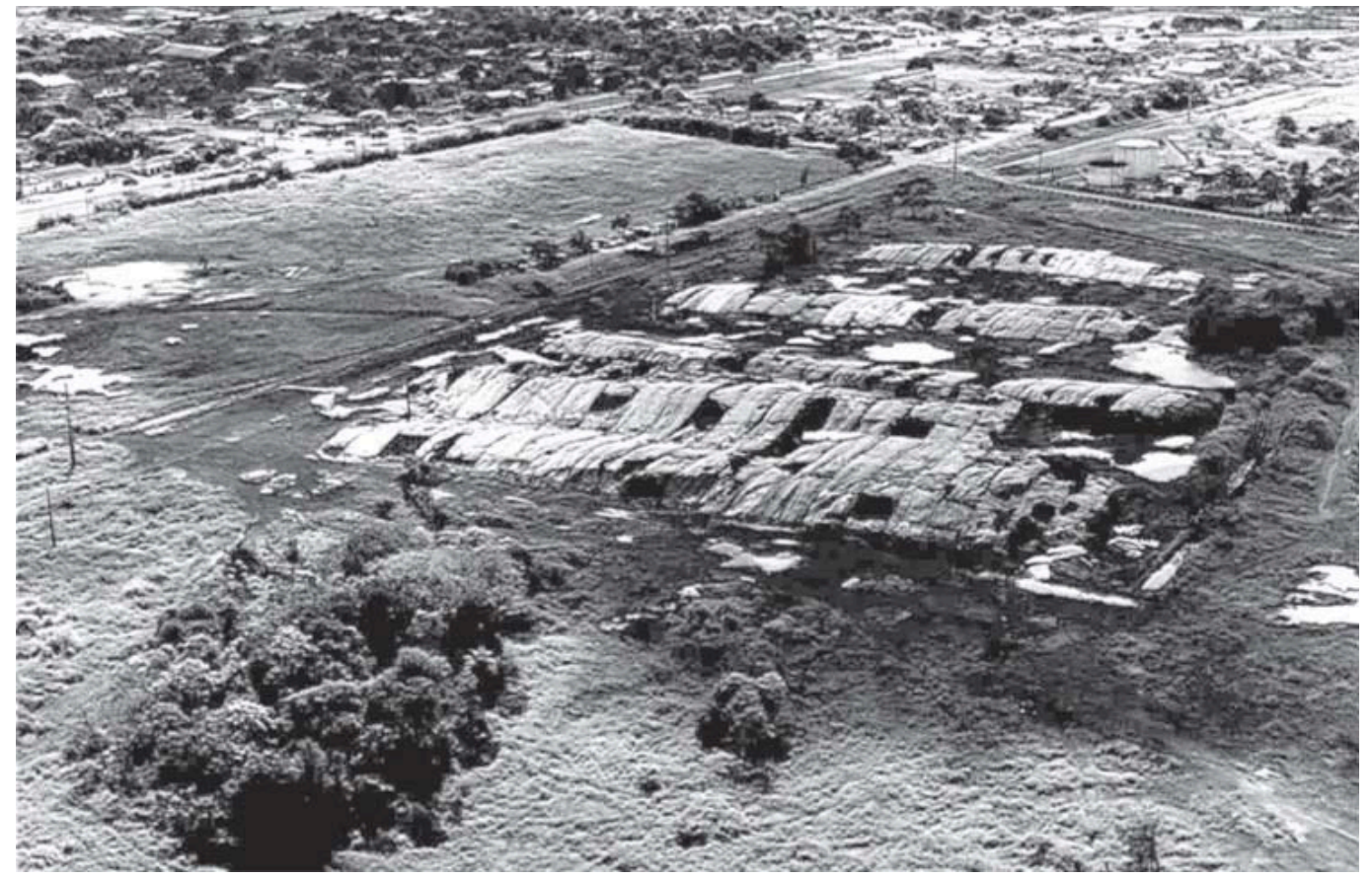

Figura 3: Depósito à superfície, no interior da área industrial, dos rejeitos retirados da bacia de rejeitos das usinas de pelotização e sinterização.

\section{Padrões de controle de arsênio}

Os padrões de controle de arsênio são definidos por normas governamentais, que seguem os padrões mundiais. As principais estão anotadas na Tabela 1. Até fins de 2000, para a água potável, eram usados os padrões definidos pela Resolução n. ${ }^{\circ}$ 20/1986, do Conselho Nacional do Meio Ambiente (CONAMA).

De acordo com a Associação Brasileira de Normas Técnicas (ABNT), os ensaios de lixiviação definem o grau de dissolução do arsênio em meio ácido, simulando condições extremas existentes em solos orgânicos. A norma 10005 (ABNT, 2004) especifica que 50 gramas da amostra devem ser colocadas em água neutra, deionizada, sendo imediatamente acidulada com ácido acético 0,5 N (solução 0,5 normal), até chegar ao pH 5. A mistura é agitada por um mínimo de 25 horas, mantendo-se o pH em $5 \pm 0,2$ com adições de ácido acético. Ao final, as soluções são completadas até 800 mililitros e amostradas para determinação do teor de arsênio. O consumo de ácido é maior onde há mais materiais que reagem com o ácido, como os minérios carbonáticos.

Segundo a norma 10006 (ABNT, 2004), os ensaios de solubilização definem o grau de dissolução do arsênio em meio neutro, de pH 7. Duas porções de 100 gramas da amostra são colocadas em água deionizada e agitadas intensamente por prazo curto, após o que se aguardam sete dias. Ao final, os volumes são completados até 400 mililitros com água deionizada e amostrados para determinação do teor de arsênio. 
Tabela 1: Padrões adotados de controle de arsênio.

\begin{tabular}{l|l|l}
\hline $\begin{array}{l}\text { Água potável para } \\
\text { consumo humano }\end{array}$ & $<0,01 \mathrm{mg} / \mathrm{L}$ & $\begin{array}{l}\text { Ministério da Saúde, Portaria n. }{ }^{\circ} 1469 / \mathrm{GM}, \\
\text { de 29 de dezembro de 2000, art. 14 }\end{array}$ \\
\hline $\begin{array}{l}\text { Água para uso } \\
\text { doméstico }\end{array}$ & $<0,05 \mathrm{mg} / \mathrm{L}$ & $\begin{array}{l}\text { CONAMA, Resolução n. }{ }^{\circ} \text { 20/1986, de 18 de } \\
\text { junho de 1986, art. 4 }\end{array}$ \\
\hline $\begin{array}{l}\text { Água de subsolo } \\
\text { Efluente descarregável } \\
\text { em drenagem }\end{array}$ & $\begin{array}{l}<\text { não há padrão definido } \\
\text { mg/L em São Paulo }\end{array}$ \\
\hline Produto inerte & $\begin{array}{l}<0,05 \mathrm{mg} / \mathrm{L} \text { na solução de ensaio } \\
\text { de solubilização }\end{array}$ & CONAMA, Resolução n. ${ }^{\circ}$ 20/86, art. 21 \\
\hline Produto não inerte & $\begin{array}{l}<5,00 \mathrm{mg} / \mathrm{L} \text { na solução de ensaio } \\
\text { de lixiviação e }>0,05 \mathrm{mg} / \mathrm{L} \text { na } \\
\text { solução de ensaio de solubilização }\end{array}$ & $\begin{array}{l}\text { ABNT, NBR 10004, NBR 10005 e NBR } \\
10006\end{array}$ \\
\hline Produto tóxico & $\begin{array}{l}>5,00 \mathrm{mg} / \mathrm{L} \text { na solução de ensaio } \\
\text { de lixiviação }\end{array}$ & ABNT, NBR 10004 e NBR 10005 \\
\hline
\end{tabular}

Caracterização dos rejeitos da pelotização e liberação de seu arsênio

O grau de liberação de arsênio dos rejeitos da pelotização foi estudado em três oportunidades: em 1998, pela JPE Engenharia em 1998, em 2000, pela Fundação Coppetec e, em 2001, pela LakefieldGeosol. Todas as amostragens foram efetuadas segundo a norma ABNT NBR 10007 e os ensaios, pelas normas ABNT NBR 1005 e NBR 1006.

Ensaios da JPE Engenharia, em 1998. Com a maior parte dos rejeitos ainda no interior da barragem, foram tomadas oito amostras da barragem e de seu entorno. Os resultados são mostrados na Tabela 2 (JAAKKO PÖYRY ENGENHARIA LTDA, 1998). Os maiores valores, das amostras R-1 e R-2, referem-se a amostras do interior da barragem. As demais foram tomadas fora do espelho de água da barragem.

Tabela 2: Resultados de ensaios de rejeitos realizados pela JPE em 1998.

\begin{tabular}{l|c|c|c|c|c|c|c|c}
\hline \multicolumn{1}{c|}{ Ensaio } & R-1 & R-2 & R-3 & R-5 & R-6 & R-7 & R-8 & R-9 \\
\hline Lixiviação $(\mathrm{mg} / \mathrm{L})$ & 0,44 & 0,86 & 0,61 & 1,7 & 1,43 & 2,46 & 0,62 & 0,09 \\
Solubilização $(\mathrm{mg} / \mathrm{L})$ & 22,8 & 40,9 & 0,23 & 8,3 & 1,48 & 1,2 & 1,42 & 0,14 \\
\hline
\end{tabular}

Ensaios da Fundação Coppetec, em 2000. Com os rejeitos retirados da bacia e estocados no pátio da área industrial, foram tomadas cinco amostras, ensaiadas para lixiviação. Os resultados são apresentados na Tabela 3 (FUNDAÇÃO COPPETEC, 2001).

Tabela 3: Ensaios de rejeitos realizados pela Fundação Coppetec em 2000.

\begin{tabular}{l|c|c|c|c|c}
\hline Ensaio & 1 & 2 & 3 & 4 & 5 \\
\hline Lixiviação $(\mathrm{mg} / \mathrm{L})$ & 0,63 & 0,2 & 0,3 & 0,49 & 0,41 \\
\hline
\end{tabular}


O exame por difração de raios-X dessas cinco amostras mostrou que eram constituídas essencialmente de óxidos e silicatos de manganês, como hausmannita, bixbyita, rodonita e tefroíta, com ausência dos hidróxidos, que foram transformados em óxidos durante a pelotização.

Ensaio da Lakefield-Geosol. Por ocasião de um estudo do material usado como aterro de ruas de Santana, realizado em 2001, mais uma amostra foi coletada da pilha de rejeitos, com a supervisão da Secretaria Estadual do Meio Ambiente (SEMA) e do Instituto Brasileiro do Meio Ambiente e dos Recursos Naturais Renováveis (IBAMA). Ela foi examinada pelo laboratório Lakefield-Geosol, de Belo Horizonte. Os resultados são apresentado na Tabela 4 (LAKEFIELD-GEOSOL, 2001). Nessa ocasião, a amostra foi também analisada para seus teores de arsênio, manganês e ferro, o que permitiu conhecer sua composição química inicial e o grau de liberação do arsênio durante o ensaio.

Com base nos teores iniciais de arsênio, sabe-se quanto de arsênio havia nas amostras submetidas aos ensaios. Havia 104 mg e 208 mg, respectivamente, nos volumes submetidos aos ensaios de lixiviação e de solubilização. Conhecendo-se os teores finais dos ensaios - 0,99 mg/L na lixiviação e 1,85 mg/L na solubilização -, foi calculado quanto do arsênio contido nas amostras foi dissolvido. No ensaio de lixiviação, foram dissolvidas 0,79 das $104 \mathrm{mg}$ iniciais, ou seja, 0,76\%; no ensaio de solubilização, foram dissolvidas 0,74 das 208 mg iniciais, ou seja, 0,36\%. Nos dois casos, foi dissolvido menos de $1 \%$ do arsênio contido nas amostras.

Tabela 4: Resultados do ensaio de rejeito realizado pela Lakefield-Geosol em 2001.

\begin{tabular}{c|c|c|c|c|c|c|cc|c|c}
\hline \multicolumn{3}{c|}{ Teores } & \multicolumn{5}{c|}{ Ensaio de lixiviação } & \multicolumn{3}{c}{ Ensaio de solubilização } \\
\hline Mn & As & Fe & As & As & As & As & As & As & As & As \\
\hline$\%$ & ppm & $\%$ & $\begin{array}{c}\text { na } \\
\text { amostra } \\
(\mathrm{mg})\end{array}$ & $\begin{array}{c}\text { na } \\
\text { solução } \\
\text { obtida } \\
(\mathrm{mg} / \mathrm{L})\end{array}$ & $\begin{array}{c}\text { lixiviado } \\
(\mathrm{mg})\end{array}$ & $\begin{array}{c}\text { lixiviado } \\
(\mathrm{em} \%)\end{array}$ & $\begin{array}{c}\text { na } \\
\text { amostra } \\
(\mathrm{mg})\end{array}$ & $\begin{array}{c}\text { na } \\
\text { solução } \\
\text { obtida } \\
(\mathrm{mg} / \mathrm{L})\end{array}$ & $\begin{array}{c}\text { solubilizado } \\
(\mathrm{mg})\end{array}$ & $\begin{array}{c}\text { solubilizado } \\
(\%)\end{array}$ \\
\hline 35,3 & 2.080 & 13,1 & 104 & 0,99 & 0,79 & 0,762 & 208 & 1,85 & 0,74 & 0,356 \\
\hline
\end{tabular}

Interpretação dos ensaios. Os ensaios da Fundação Coppetec e da Lakefield-Geosol, com amostras dos rejeitos já fora da barragem, mostram que eles (1) não são tóxicos, isto é, os teores dos ensaios de lixiviação são inferiores a 5 mg/L, porém (2) não são inertes, visto que apresentaram teores superiores a 0,05 mg/L nos ensaios de solubilização. 
Tabela 5: Ensaios de minérios realizados pela Lakefield-Geosol em 2001.

\begin{tabular}{|c|c|c|c|c|c|c|c|c|c|c|c|}
\hline \multirow{4}{*}{ Amostra } & \multicolumn{3}{|c|}{ Teores } & \multicolumn{4}{|c|}{ Ensaios de lixiviação } & \multicolumn{4}{|c|}{ Ensaios de solubilização } \\
\hline & \multirow[b]{2}{*}{$\mathrm{Mn}$} & \multirow[b]{2}{*}{ As } & \multirow[b]{2}{*}{$\mathrm{Fe}$} & As & As & As & As & As & As & As & As \\
\hline & & & & $\begin{array}{c}\text { na } \\
\text { amostra }\end{array}$ & $\begin{array}{c}\text { na } \\
\text { solução } \\
\text { obtida }\end{array}$ & lixiviado & lixiviado & $\begin{array}{c}\text { na } \\
\text { amostra }\end{array}$ & $\begin{array}{c}\text { na } \\
\text { solução } \\
\text { obtida }\end{array}$ & solubilizado & solubilizado \\
\hline & $\%$ & $\mathrm{ppm}$ & $\%$ & (mg) & $(\mathrm{mg} / \mathrm{L})$ & (em mg) & (em \%) & (mg) & $(\mathrm{mg} / \mathrm{L})$ & $(\mathrm{mg})$ & $(\%)$ \\
\hline G30 & 29 & 1.516 & 15 & 75,80 & 0,01 & 0,01 & 0,011 & 151,6 & 0,01 & 0,04 & 0,003 \\
\hline BM36 & 26 & 1.364 & 15 & 68,20 & 0,01 & 0,01 & 0,012 & 136,4 & 0,01 & 0,04 & 0,003 \\
\hline M30 & 30 & 1.558 & 14 & 77,90 & 0,01 & 0,01 & 0,010 & 155,8 & 0,01 & 0,04 & 0,003 \\
\hline M28 & 29 & 1.499 & 13 & 74,95 & 0,01 & 0,01 & 0,011 & 149,9 & 0,01 & 0,04 & 0,003 \\
\hline M26 & 26 & 1.549 & 14 & 77,45 & 0,01 & 0,01 & 0,010 & 154,9 & 0,01 & 0,04 & 0,003 \\
\hline M20 & 25 & 1.356 & 13 & 67,80 & 0,01 & 0,01 & 0,012 & 135,6 & 0,01 & 0,04 & 0,003 \\
\hline MCE & 17 & 1.415 & 5 & 70,75 & 0,07 & 0,06 & 0,079 & 141,5 & 0,47 & 0,19 & 0,133 \\
\hline
\end{tabular}


Caracterização da liberação do arsênio de minérios óxido e carbonato

Ensaios semelhantes foram efetuados em 2001 com amostras tomadas de pilhas de minérios beneficiados e classificados da Serra do Navio, obtendo-se pela Lakefield-Geosol (2001) os resultados da Tabela 5. Foram amostrados minério óxido grosso (G30), óxido bitolado miúdo (BM36), óxido miúdo (M30, M28, M26 e M20) e minério carbonato (MCE).

O arsênio é muito estável nos minérios óxidos, apresentando teores de 0,01 mg/L nos ensaios de lixiviação e de solubilização. Já o minério carbonático, sendo primário, apresenta valores maiores nas soluções, principalmente na solução ácida do ensaio de lixiviação, porém ainda se qualifica como não tóxico e não inerte.

\section{Arsênio em águas de subsolo na área industrial da ICOMI}

Ao identificar a liberação de arsênio na barragem de rejeitos da usina de pelotização e a infiltração de parte desse arsênio no nível freático ao redor da barragem, a ICOMI instalou uma rede de poços para monitorar as águas de subsolo, a qual tem sido amostrada sistematicamente desde 1997 (Figuras 4 e 5). Essa rede de poços, aberta e mantida com a melhor técnica, cobre todo o entorno da barragem e outros setores onde havia pilhas de minério, havendo ainda poços fora da área industrial, principalmente na área da Vila Elesbão.

A amostragem e a análise das águas dos poços de monitoramento foram iniciadas pela Jaakko Pöyry, posteriormente substituída pela JPE Engenharia, sua sucessora. A partir de 2001, os poços passaram a ser monitorados pela AMPLA Engenharia. No momento, a AMPLA amostra também poços de coleta de água de particulares, situados a leste, ao norte e a oeste da área industrial da ICOMI (Figura 5).

O grau de precisão das análises da Jaakko Pöyry foi de 0,05 mg/L, compatível com os limites de potabilidade estabelecidos pela Resolução n. ${ }^{\circ}$ 20/1986 do CONAMA. Valores inferiores a esse foram reportados como $<0,05 \mathrm{mg} / \mathrm{L}$.

O grau de precisão das análises reportadas pela AMPLA é de 0,002 mg/L, compatível com o teor máximo de 0,01 mg/L em água para consumo humano especificado pela Portaria n. ${ }^{\circ}$ 1469/GM, de 29 de dezembro de 2000, do Ministério da Saúde.

As Figuras 4 e 5, preparadas com os dados apresentados pela JPE Engenharia (2001) e pela AMPLA (2002), apresentam a localização dos poços de monitoramento e os resultados neles obtidos na primeira amostragem, de agosto de 1997, e na última, de abril de 2002, permitindo notar a redução dos valores no decorrer desse período. 

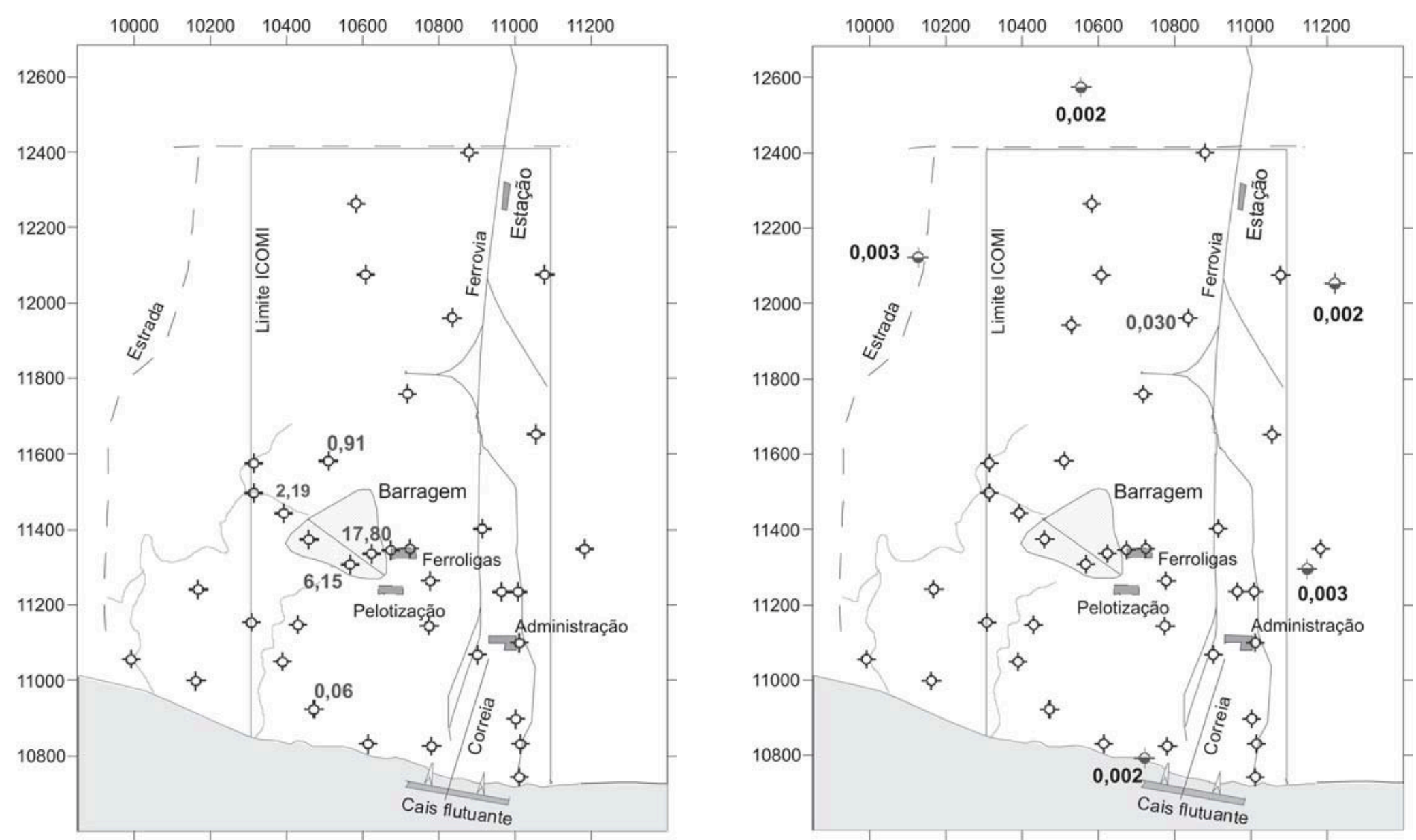

Figura 4 e Figura 5: Arsênio, em miligramas por litro, em águas de subsolo, amostradas em poços abertos para monitoramento (branco) e em poços de coleta de água para consumo (cinza). 
Os teores maiores que 0,05 mg/L em 2001 e maiores que 0,010 mg/L em 2002 estão anotados. Os poços sem anotação de valores apresentaram teores abaixo desses limites.

Os maiores teores foram observados em 1997, em dois poços abertos no fundo da barragem de rejeito e próximos dos pontos de descargas das usinas. Naquela ocasião, eles apresentavam concentrações de 6,15 e 17,80 mg/L de arsênio. Outros dois poços, a menos de $100 \mathrm{~m}$ da barragem, apresentaram valores de 2,19 e 0,91 mg/L de arsênio. Em 2002 todos esses poços estavam com menos de 0,01 mg/L.

Nenhum dos poços situados fora da área industrial apresentou valores superiores a 0,05 mg/L em 1997 e/ou superiores a 0,01 mg/L em 2002. O mesmo ocorreu com os poços localizados ao longo do limite oeste da área industrial.

O reduzido fluxo do arsênio para fora da região da barragem é explicável pela alta concentração de colóides no interior da barragem. Como ocorreu durante a gênese do minério, os colóides retiveram o arsênio e evitaram sua remoção em solução. Daí a limitação da contaminação nas imediações da barragem.

A Figura 4, mostra os resultados da amostragem efetuada pela Jaakko Pöyry Engenharia em agosto de 1997. Estão anotados, todos os resultados superiores a 0,05 mg/L (limite de análise à época), os quais ocorreram em cinco poços de monitoramento próximos à barragem de rejeitos. Na Figura 5, apresentam-se os resultados da última amostragem efetuada pela AMPLA Engenharia, em abril de 2002. Ausência de valores significa teores menores que $0,01 \mathrm{mg} / \mathrm{L}$; somente um poço apresentou valor superior a $0,01 \mathrm{mg} / \mathrm{L}$. Nenhum poço usado para a coleta de água para consumo apresentou valor superior a 0,003 mg/L.

\section{Arsênio em pontos de tomada de água para consumo}

Resultados de amostragens efetuadas pela AMPLA de pontos de tomada de água para água de consumo estão apresentados na Figura 6. Por eles nota-se que os teores de arsênio são maiores no rio Amazonas que nos poços abertos por particulares a oeste, ao norte e a leste da área industrial. Nota-se também que os valores variam muito no decorrer do ano, sendo maiores nas estações mais chuvosas. Os resultados indicam que o rio Amazonas é importante transportador de arsênio.

As concentrações de arsênio são maiores nas amostras do rio Amazonas, com picos em ocasiões de maior fluxo de água. 


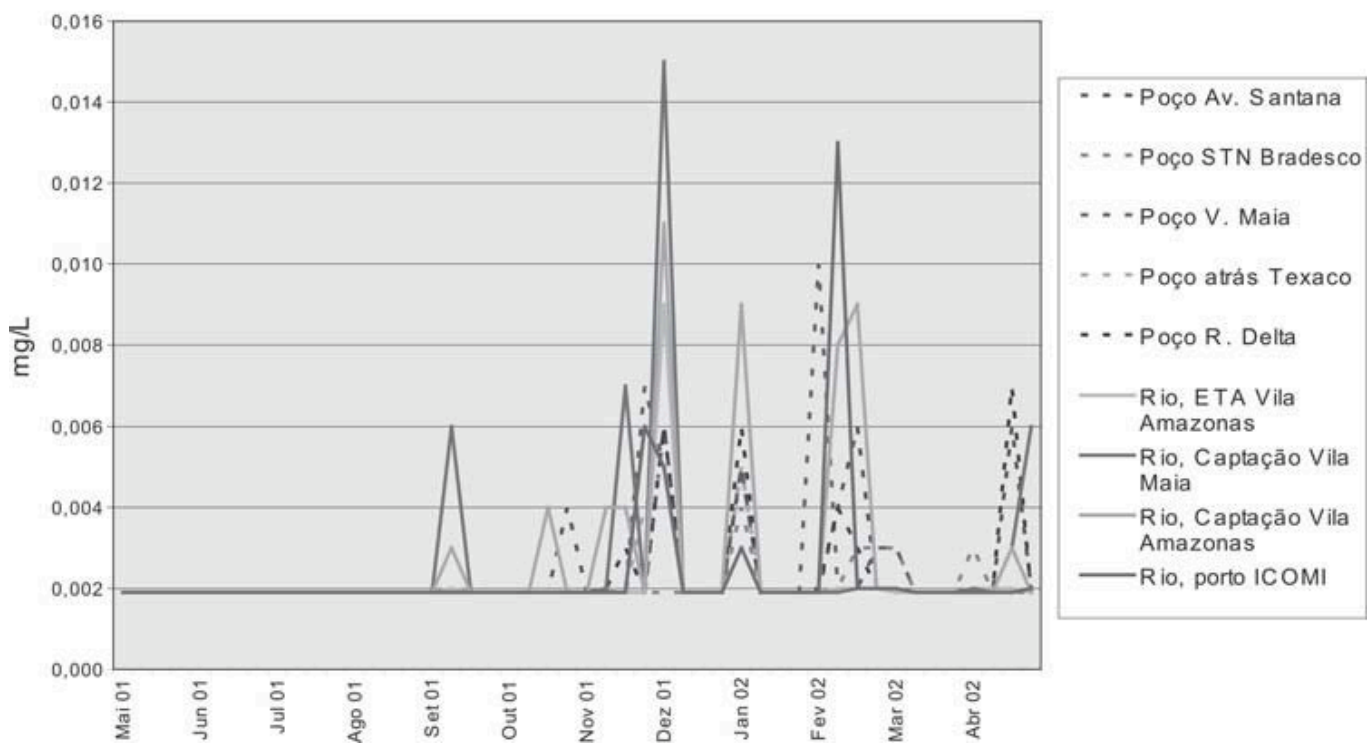

Figura 6: Valores de arsênio em água coletada para consumo em quatro pontos do rio Amazonas e em cinco poços ao redor da área industrial.

\section{Arsênio em drenagem}

O monitoramento executado pela JPE Engenharia e pela AMPLA Engenharia incluiu a amostragem de águas de drenagens que partem da região da barragem. Como a JPE interrompeu o monitoramento em 2001, estão apresentados nas Figuras 7 e 8 os resultados obtidos pela AMPLA, os quais são muito similares aos da JPE Engenharia.

Até 1998, enquanto os rejeitos da pelotização estavam na barragem, os igarapés Elesbão I, no interior da área industrial, e Elesbão II, a oeste da área industrial, apresentaram valores superiores aos adotados para água potável, porém com os valores caindo muito em direção ao rio Amazonas. A redução de valores deve-se à diluição com águas sem arsênio e à oxidação natural do arsênio dissolvido. Em abril de 2002, todos os valores no igarapé Elesbão II eram inferiores a 0,03 mg/L, havendo ainda dois valores mais altos no igarapé Elesbão I, no interior da área industrial. Esses teores devem continuar a decrescer.

Amostragens executadas e reportadas pela AMPLA Engenharia Ltda. Estão salientados os valores superiores a 0,050 mg/L. 

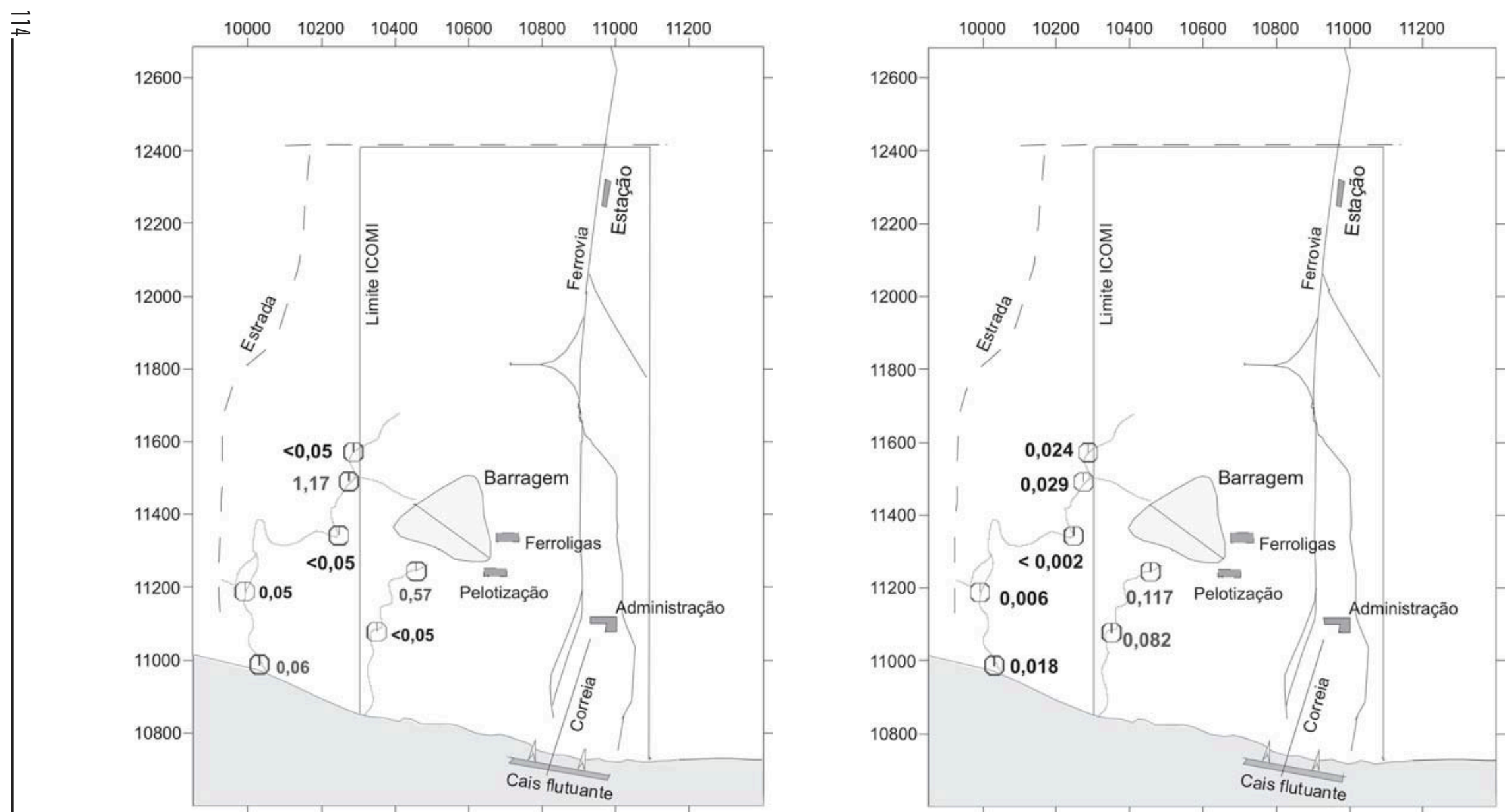

Figura 7 e Figura 8: Arsênio, em miligramas por litro, em águas dos igarapés Elesbão II (fora da área industrial) e Elesbão I (no interior da área industrial), em setembro de 1997 (à esquerda) e abril de 2002 (à direita). 


\section{Arsênio e os moradores da Vila Elesbão}

Devido à divulgação da contaminação por arsênio na área industrial e de teores anômalos no igarapé Elesbão II, houve natural preocupação do Governo do Estado quanto à possível contaminação dos moradores dos setores ao norte e a oeste da área industrial, que constituem a Vila Elesbão.

Para verificar a possibilidade de haver moradores contaminados por arsênio, foi chamado o Instituto Evandro Chagas, da Fundação Nacional da Saúde, que, com uma equipe de 19 pessoas, pesquisou 2.045 pessoas residentes em Vila Elesbão e nos locais Delta, Piçarreira, Estação, Matapi Grande e Matapi Mirim, todos vizinhos da área industrial. O estudo registrou a escolaridade, o histórico, as ocupações e os costumes dessas pessoas, das quais foram tomadas amostras de sangue e de cabelo, para exame de arsênio.

O livro Arsenic and Arsenic Compounds, da World Health Organization (WHO, 2001), das Nações Unidas, traz importantes observações a considerar, algumas das quais estão resumidas a seguir.

Arsênio no corpo humano. O arsênio é um elemento comum na natureza, sendo absorvido principalmente com água, embora possa também ser absorvido com alimentos, gases e pó. Em doses baixas, ele é metabolizado e eliminado com a urina. O arsênio em compostos orgânicos, isto é, associado a carbono, é mais facilmente eliminado pela urina. O arsênio inorgânico, isto é, proveniente diretamente de minerais, tem metabolização mais difícil e, quando ingerido em doses maiores, o excesso pode ficar retido em órgãos do corpo humano, podendo ser carcinogênico. O arsênio pentavalente, o do minério óxido de manganês, é menos nocivo que o trivalente. O hábito de fumar aumenta a assimilação de arsênio. Peixes acumulam arsênio com eficiência, mas esse arsênio é freqüentemente orgânico, menos maléfico que o inorgânico. Peixes de mar têm mais arsênio que os de água doce.

Arsênio no sangue. Devido à facilidade de eliminação, o valor de arsênio encontrado no sangue representa o arsênio ingerido nas últimas semanas, comumente representando o contido na água e nos alimentos. É um bom indicador das condições vigentes no meio ambiente.

Arsênio em cabelo e unhas. O valor de arsênio em cabelo e unhas representa a quantidade de arsênio fixada no organismo nos últimos anos ou meses. Pode indicar surtos de alta contaminação, periódicos ou constantes.

Valores padrão. A WHO não indica concentrações de arsênio para serem usadas como padrão. Da leitura de Arsenic and Arsenic Compounds, deduz-se que a existência de muitas variáveis (arsênio orgânico ou inorgânico, características fisiológicas dos indivíduos, alimentos mais ricos ou mais pobres em arsênio, água com mais ou menos arsênio etc.) inibe a definição de padrões. 
Primeiros resultados do Instituto Evandro Chagas. Em dezembro de 2001, o Instituto Evandro Chagas apresentou seus primeiros resultados de análises de 1.377 pessoas para sangue e 512 para cabelo. Os resultados divulgados expressaram médias de grupos, segundo uma classificação por idade e uma por local de moradia. Com base em estudos anteriores na Amazônia, foi especificado que pessoas não expostas, ou seja, não contaminadas, poderiam apresentar até 1 a 2 ppm (mg/L) de arsênio no cabelo e de 1 a 5,1 ìg/L (ppb, ou mg/m $\mathrm{m}^{3}$ ) no sangue.

Os dados então divulgados foram utilizados para o preparo das Figuras 9 e 10, que mostram a distribuição dos valores médios de arsênio no sangue e no cabelo para as populações amostradas. A escala de valores, à direita dos gráficos, é logarítmica.

Conforme mostra a Figura 9, a distribuição de arsênio pelas faixas etárias é muito homogênea nos indivíduos amostrados. As médias são inferiores a $300 \mathrm{ppb}(0,30 \mathrm{ppm}$ ou $300 \mathrm{ìg} / \mathrm{L})$ no cabelo e a 6,5 ppb $(0,006 \mathrm{ppm}$ ou 6,5 ìg/L) no sanque.

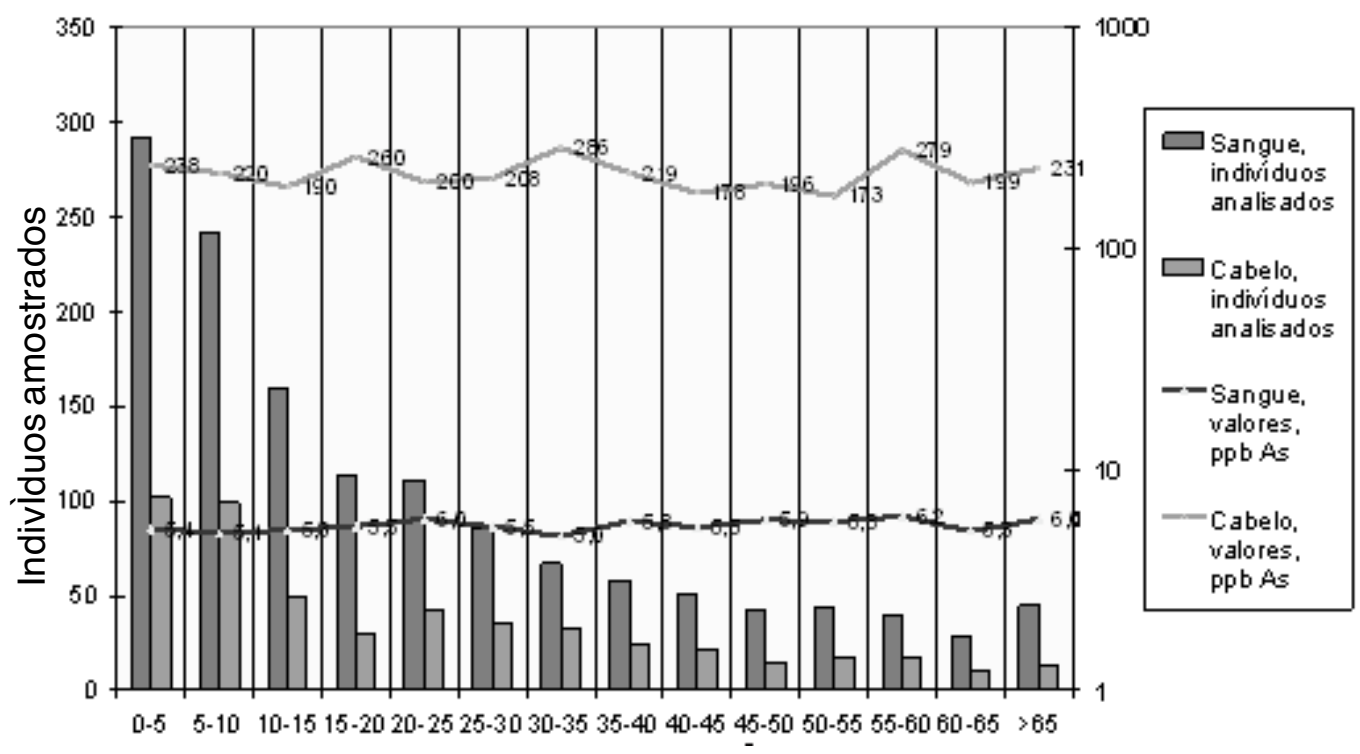

Figura 9: Distribuição de arsênio em partes por bilhão (ppb) no sangue de 1.377 pessoas e no cabelo de 512 pessoas da Vila Elesbão, conforme a faixa etária.

Fonte: INSTITUTO EVANDRO CHAGAS (2001).

A Figura 10 mostra os valores segundo os locais de moradia. Notase que os valores no cabelo são levemente menores nas pessoas que moram em Piçarreira, Matapi, Santana e Estação, locais mais distantes do rio Amazonas.

Em abril de 2002, o Instituto Evandro Chagas apresentou novo relatório, relatando ter observado médias globais de 0,56ìg/g (560 ppb) no cabelo de 1.986 pessoas e de 5,95 ìg/L (5,95 ppb) no sangue de 
1.927 pessoas. Não foram apresentados resultados individuais ou médias setoriais.

O Instituto declarou que "não houve diferença estatisticamente significante entre as concentrações de As em sangue ou cabelo segundo a idade, tempo de moradia, local de residência, anos de estudo e ocupação das pessoas" (INSTITUTO EVANDRO CHAGAS, 2002). Declarou também que não encontrou na população, "como um todo, indícios de pessoas com problemas de saúde em decorrência da exposição ao arsênio" (INSTITUTO EVANDRO CHAGAS, 2002). Informou ainda que "existem 67 pessoas com teores de As em sangue acima de valores citados na literatura internacional (10 ppb), os quais serão reinvestigados visando determinar as concentrações de As orgânico e inorgânico (especiação do As), permitindo concluir a avaliação desses indivíduos. No caso de As em cabelo, nenhum indivíduo apresentou teores acima de 2 ppm" (INSTITUTO EVANDRO CHAGAS, 2002).

Em sua conclusão final, o Instituto informa: "As patologias identificadas na comunidade do Elesbão através da análise clínicoepidemiológica laboratorial não apresentam relação estatística significativa com as médias de arsênio encontradas no sangue e no cabelo da população estudada" (INSTITUTO EVANDRO CHAGAS, 2002).

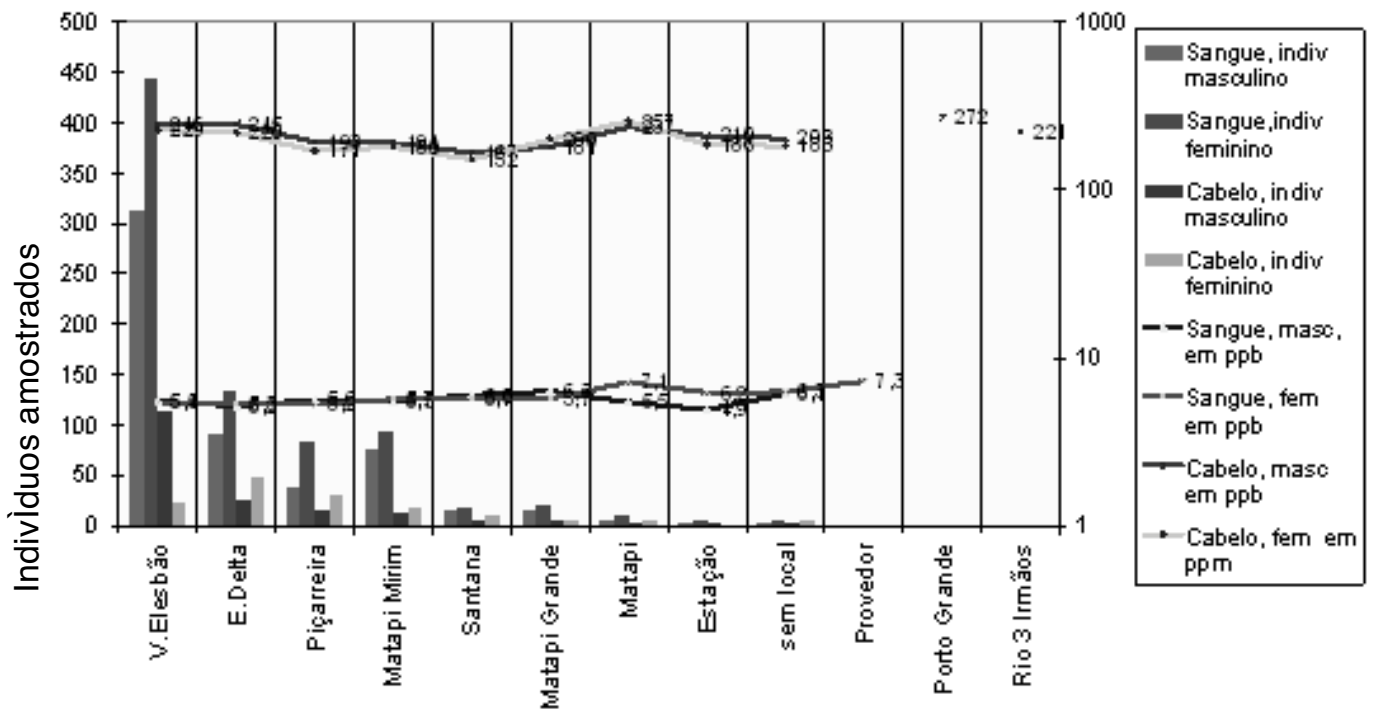

Figura 10: Distribuição de arsênio em partes por bilhão (ppb) no sangue de 1.377 pessoas e no cabelo de 512 pessoas da Vila Elesbão, segundo o local de moradia.

Fonte: INSTITUTO EVANDRO CHAGAS (2001).

O Instituto, portanto, não encontrou pessoas organicamente contaminadas por arsênio, porém encontrou 67 pessoas com teor relativamente alto de arsênio no sangue. Em função da observação feita 
com base na Figura 10 - pessoas que moram mais perto do Amazonas têm maiores teores de arsênio no cabelo -, conviria também examinar os locais de moradia dessas 67 pessoas.

\section{Arsênio em minérios usados na pavimentação de ruas de Santana}

Em 1997, a municipalidade de Santana solicitou à ICOMI um volume de minérios para "utilização na composição de concreto asfáltico, para emprego em vias do município". Ao invés de dar ao material cedido a destinação declarada, a municipalidade usou-o como revestimento direto de algumas ruas de Santana. Posteriormente, talvez devido ao conhecimento da contaminação de arsênio no entorno da barragem de rejeitos, os habitantes de algumas dessas ruas ficaram preocupados com a possibilidade de sofrer contaminação por arsênio.

Para esclarecimento e tranqüilidade desses moradores, a ICOMI providenciou, juntamente com a SEMA e o IBAMA, a amostragem desses materiais e a execução de ensaios de lixiviação e de solubilização, como os efetuados com os rejeitos. Foram 15 amostras, todas tomadas com furos de sondagem. Um geólogo da ICOMI acompanhou a amostragem e caracterizou o material amostrado (ver Tabela 6).

Tabela 6: Localização e descrição das amostras coletadas em ruas de Santana.

\begin{tabular}{c|c|l}
\hline $\begin{array}{c}\text { Furo } \\
1\end{array}$ & $\begin{array}{c}\text { Local } \\
\text { Av. das Nações }\end{array}$ & $\begin{array}{l}\text { Minério fino pardacento, com alguns fragmentos de } \\
\text { pelotas malformadas e friáveis }\end{array}$ \\
\hline 3 & Av. D. Pedro & $\begin{array}{l}\text { Minério, mistura de fragmentos de minérios óxido, } \\
\text { carbonato com alguns fragmentos de escória }\end{array}$ \\
\hline 6 & Rua Machado de Assis & Minério fino, com algumas pelotinhas malformadas \\
\hline 7 & Av. Rui Barbosa & Minério fino pulverulento \\
\hline 12 & Av. Santana & Minério miúdo, com fragmentos de minério grosso \\
\hline 14 & Rua Salvador Diniz & $\begin{array}{l}\text { Minério fino, pulverulento } \\
\text { Mistura de material terroso com minério fino, com } \\
\text { fragmentos de minérios óxido e carbonato e escória }\end{array}$ \\
\hline 4 & Rua Machado de Assis & $\begin{array}{l}\text { Mistura de material terroso emanganesifero com } \\
\text { fragmentos de minérios óxido e carbonato }\end{array}$ \\
\hline 5 & Av. Rio Branco & $\begin{array}{l}\text { Mistura de minério fino com laterita e blocos de ferro } \\
\text { liga }\end{array}$ \\
\hline 8 & Av. Coelho Neto & $\begin{array}{l}\text { Mistura de material terroso, pardo, com fragmentos } \\
\text { de escória e blocos de argila branca }\end{array}$ \\
\hline 9 & Av. Coelho Neto & $\begin{array}{l}\text { Mistura de material terroso, pardo, com fragmentos } \\
\text { de escória e blocos de argila branca }\end{array}$ \\
\hline 10 & Av. Brasilia & $\begin{array}{l}\text { Mistura de minério fino, pulverulento, com alguns } \\
\text { fragmentos de escória }\end{array}$ \\
\hline 11 & Av. Brasília & $\begin{array}{l}\text { Mistura de fragmentos de escória e minério fino } \\
\text { Mistura de minérios finos, pulverulentos, com poucas } \\
\text { pelotas } \\
\text { Aluvião, argila pegajosa e material orgânico }\end{array}$ \\
\hline 13 & 1a Avenida & Av. Brasilia
\end{tabular}


Tabela 7: Resultados de ensaios com o revestimento de ruas de Santana realizados pela Lakefield-Geosol em 2001.

\begin{tabular}{|c|c|c|c|c|c|c|c|c|c|c|c|}
\hline \multirow{4}{*}{ Amostra } & \multicolumn{3}{|c|}{ Teores } & \multicolumn{4}{|c|}{ Ensaios de lixiviação } & \multicolumn{4}{|c|}{ Ensaios de solubilização } \\
\hline & \multirow[b]{2}{*}{$\mathrm{Mn}$} & \multirow[b]{2}{*}{ As } & \multirow[b]{2}{*}{$\mathrm{Fe}$} & As & As & As & As & As & As & As & As \\
\hline & & & & $\begin{array}{c}\text { na } \\
\text { amostra }\end{array}$ & $\begin{array}{c}\text { na } \\
\text { solução } \\
\text { obtida }\end{array}$ & lixiviado & lixiviado & $\begin{array}{c}\text { na } \\
\text { amostra }\end{array}$ & $\begin{array}{c}\text { na } \\
\text { solução } \\
\text { obtida }\end{array}$ & solubilizado & solubilizado \\
\hline & $\%$ & ppm & $\%$ & $(\mathrm{mg})$ & $(\mathrm{mg} / \mathrm{L})$ & $\begin{array}{l}(\mathrm{em} \\
\mathrm{mg})\end{array}$ & (em \%) & (mg) & $(\mathrm{mg} / \mathrm{L})$ & $(\mathrm{mg})$ & (\%) \\
\hline 1 & 32,1 & 1.566 & 18 & 78,30 & 0,04 & 0,03 & 0,041 & 156,6 & 0,35 & 0,140 & 0,089 \\
\hline 6 & 39,9 & 1.937 & 16,5 & 96,85 & 0,08 & 0,06 & 0,066 & 193,7 & 0,23 & 0,090 & 0,046 \\
\hline 7 & 37,5 & 1.777 & 13,4 & 88,85 & 0,07 & 0,06 & 0,063 & 177,7 & 0,29 & 0,114 & 0,064 \\
\hline 12 & 41,8 & 1.684 & 7,7 & 84,20 & 0,01 & 0,01 & 0,010 & 168,4 & 0,01 & 0,004 & 0,002 \\
\hline 14 & 42,3 & 1.996 & 13,9 & 99,80 & 0,06 & 0,05 & 0,048 & 199,6 & 0,31 & 0,124 & 0,062 \\
\hline 2 & 39,9 & 1.305 & 9,1 & 65,25 & 0,02 & 0,02 & 0,025 & 130,5 & 0,17 & 0,066 & 0,051 \\
\hline 8 & 23,4 & 291 & 3,3 & 14,55 & 0,01 & 0,01 & 0,055 & 29,1 & 0,24 & 0,096 & 0,330 \\
\hline 9 & 17,2 & 116 & 1,7 & 5,80 & 0,01 & 0,01 & 0,138 & 11,6 & 0,19 & 0,074 & 0,638 \\
\hline 10 & 32,7 & 935 & 8,9 & 46,75 & 0,05 & 0,04 & 0,086 & 93,5 & 0,42 & 0,166 & 0,178 \\
\hline 11 & 26,6 & 339 & 3,5 & 16,95 & 0,03 & 0,02 & 0,142 & 33,9 & 0,4 & 0,160 & 0,472 \\
\hline 13 & 40,7 & 1.785 & 14,8 & 89,25 & 0,12 & 0,10 & 0,108 & 178,5 & 0,48 & 0,192 & 0,108 \\
\hline
\end{tabular}


Seis das amostras compunham-se de misturas de vários tipos de minérios naturais, provavelmente restos de pilhas, mais terra e argilas. Oito das amostras eram compostas de misturas de materiais manganesíferos, que incluíam restos de minérios naturais com aparas de escórias de pelotas, sínter e ferros-ligas, mais quantidades variáveis de terra, laterita e argilas. Uma das amostras era composta de aluvião natural do local.

As amostras foram ensaiadas por lixiviação e por solubilização pelo laboratório Lakefield-Geosol, segundo a metodologia definida pelas normas ABNT NBR 10005 e 10006 (ver Tabela 7).

A média de teor da solução resultante dos ensaios de solubilização das seis amostras mais ricas em minério foi de $0,20 \mathrm{mg} / \mathrm{L}$, enquanto a das oito amostras com mais mistura de restos das operações metalúrgicas foi de 0,51 mg/L. Foram solubilizados, respectivamente, 0,045\% e 0,253\% do arsênio contido nas amostras.

\section{Os ensaios demonstraram que nenhuma das amostras é tóxica.}

As amostras 3 e 12 são classificáveis como inertes (com menos de 0,05 mg/L no ensaio de solubilização), e as demais são classificáveis como não inertes, por apresentarem mais de 0,05 mg/L no ensaio de solubilização. Convém notar que os ensaios de solubilização, realizados em meio ácido similar ao que ocorre na natureza no Amapá, apresentaram menores teores em solução, o que sugere que a classificação proposta é conservadora. Com exceção da amostra 5, as soluções não alcançaram $0,50 \mathrm{mg} / \mathrm{L}$ de arsênio e, pela Resolução n. ${ }^{\circ}$ 20/86 do CONAMA, poderiam ser descarregadas diretamente em drenagem. Os ensaios confirmaram o baixo grau de dissolubilidade do arsênio dos materiais amostrados, restringindo-se aos átomos desse elemento situados na periferia dos fragmentos das amostras.

Os resultados da amostra 5 indicam a possibilidade de conter algo dos rejeitos da pelotização. De qualquer forma, os ensaios indicam que o material não é tóxico, é não inerte e que a água nele contida não é potável. O teor da solução solubilizada, ao pH 7, chegou a 1,80 mg/L, enquanto a solução lixiviada, ao pH 5,08, chegou a 0,80 mg/L. Considerando-se que o $\mathrm{pH}$ de Santana pode estar entre 5 e 6, esse último valor deve estar mais próximo da realidade.

\section{Fatores de diluição das águas que atravessam os pavimentos}

O capeamento das ruas e avenidas está fortemente compactado, sendo mais impermeável que os terrenos expostos entre elas. Devido à compactação, a maior parte das águas de chuva drena para fora dos capeamentos e é escoada ou penetra no solo sem oportunidade de penetrar pelo capeamento. O fator dessa diluição é de difícil quantificação, mas sem dúvida é significativo. 
O capeamento não se superpõe ao nível freático de forma extensiva, mas apenas às ruas e avenidas com ele pavimentadas, as quais correspondem a 10\%, se tanto, da área total dos bairros ou quarteirões envolvidos. O fato de a área capeada corresponder a um décimo da área total resulta num fator de diluição de pelo menos 10 vezes das águas que atravessam o capeamento.

Entre o capeamento e o nível freático, há uma camada de solo que inevitavelmente dilui qualquer volume de água que atravesse o capeamento. A quantificação dessa diluição é também difícil.

\section{Estimativa grosseira do arsênio eventualmente solubilizado na área industrial}

Nos ensaios descritos, foi observado que o minério óxido, sem misturas, apresenta fator de solubilização de 0,003\% do arsênio nele contido, enquanto o minério carbonático tem lixiviação de 0,013\% do arsênio nele contido (Tabela 5). O arsênio novo liberado dos carbonatos é absorvido pelos novos óxidos manganesíferos, que continuam formando-se ao decomporem-se os mármores. Quaisquer solubilizações de arsênio que ocorram na Serra do Navio e que não sejam assimiladas pelo minério são diluídas na drenagem e levadas ao mar pelos rios Amapari e Araguari.

Os ensaios com amostras de minérios, de rejeitos da pelotização, misturas de restos da pelotização e sinterização e restos de minério e restos de minérios mostraram os seguintes valores médios de solubilização (Tabelas 4, 5 e 7):

rejeitos da pelotização

misturas de minérios e pelotização restos de minérios minério carbonato minério óxido
0,356\% do arsênio contido foi solubilizado

0,253\% do arsênio contido foi solubilizado 0,045\% do arsênio contido foi solubilizado 0,133\% do arsênio contido foi solubilizado 0,003\% do arsênio contido foi solubilizado

Entre 1957 e 1997, foram embarcados pelo porto de Santana 34.127.862 toneladas de minérios e produtos manganesíferos, contendo 56.784 toneladas de arsênio, conforme discriminado na Tabela 8.

Todos esses produtos ficaram pouco tempo expostos à intempérie, visto que foram embarcados em navios logo após sua chegada ao porto ou sua produção. Nas ocasiões em que não eram carregados nos navios diretamente dos trens, eram estocados em pilhas por, no máximo, algumas semanas.

O mesmo não se pode dizer dos rejeitos da produção de pelotas e sínter, que totalizam 75.600 toneladas e que ainda estão no porto de Santana. Esse produto é em parte artificial e tem o maior índice de 
solubilização de arsênio de todos os considerados, sendo a fonte da contaminação que ocorreu na lagoa de rejeitos da usina de pelotização. Os ensaios de solubilização mostraram liberação de 0,356\% do arsênio nele contido. Considerando-se que os rejeitos têm historicamente média de 0,19\% de arsênio, a quantidade de arsênio que as 75.600 podem ter liberado é da ordem de 511 quilogramas (75.600 t 0,19\% de As 0,356\% de liberação do arsênio), conforme mostra a Tabela 9. Esse montante ficou retido na região da barragem de rejeitos e aos poucos tem sido neutralizado, por precipitação juntamente com óxidos e hidróxidos de ferro e manganês neoformados.

Tabela 8: Produção comercializada.

\begin{tabular}{lr|c|r}
\hline \multicolumn{1}{c|}{ Produto } & \multicolumn{1}{c|}{ Toneladas } & \% de As & t de As contido \\
\hline $\begin{array}{l}\text { Minérios óxidos, naturais, } \\
\text { provenientes da Serra do Navio }\end{array}$ & $31.251 .935 \mathrm{t}$ & $0,17 \%$ & 53.128 \\
$\begin{array}{l}\text { Minérios carbonatos, naturais, } \\
\text { provenientes da Serra do Navio }\end{array}$ & $926.369 \mathrm{t}$ & $0,10 \%$ & 926 \\
$\begin{array}{l}\text { Pelotas industriais, produzidas } \\
\text { em Santana }\end{array}$ & $1.273 .883 \mathrm{t}$ & $0,14 \%$ & 1.784 \\
$\begin{array}{l}\text { Sinter e ligas industriais, } \\
\text { produzidas em Santana }\end{array}$ & $675.675 \mathrm{t}$ & $0,14 \%$ & 946 \\
\hline \multicolumn{1}{c}{ Total } & $\mathbf{3 4 . 1 2 7 . 8 6 2 \mathrm { t }}$ & $\mathbf{0 , 1 7 \%}$ & $\mathbf{5 6 . 7 8 4}$ \\
\hline
\end{tabular}

É mais difícil estimar quanto poderia ter sido eventualmente solubilizado dos produtos vendidos, visto que sua permanência na área do porto foi muito curta. Para chegar a uma quantificação inicial, ainda que insegura, poder-se-ia considerar que ocorreu uma eventual solubilização de um décimo (10\%) da solubilização medida com os ensaios executados atendendo às normas da ABNT. Como exemplo, para minérios óxidos naturais, cuja solubilização medida é de 0,003\% do arsênio neles contido, poder-se-ia considerar que ocorreu solubilização de um décimo desse valor, ou seja, de 0,0003\% do arsênio contido no minério.

Tabela 9: Solubilização máxima de arsênio no porto de Santana.

\begin{tabular}{|c|c|c|c|c|c|c|c|}
\hline Produto & Total (t) & $\begin{array}{c}\text { Teor } \\
\text { de } \\
\text { arsênio } \\
(\% \mathrm{As}) \\
\end{array}$ & $\begin{array}{l}\text { Arsênio } \\
\text { contido } \\
\text { (t) }\end{array}$ & $\begin{array}{c}\text { Solubilização } \\
\text { máxima } \\
\text { medida (\% } \\
\text { do As) }\end{array}$ & \begin{tabular}{|c|} 
Solubilização \\
máxima \\
possível (\% \\
do As)
\end{tabular} & $\begin{array}{c}\text { Arsênio } \\
\text { solubilizável } \\
\text { (kg) }\end{array}$ & Periodo \\
\hline $\begin{array}{l}\text { Óxido } \\
\text { natural }\end{array}$ & 31.251 .935 & $0,17 \%$ & 53.128 & $0,00 \%$ & $0,00 \%$ & 531 & 1957-199 \\
\hline $\begin{array}{l}\text { Carbonato } \\
\text { natural }\end{array}$ & 926.369 & $0,10 \%$ & 926 & $0,13 \%$ & $0,01 \%$ & 120 & 1985-199 \\
\hline Pelotas & 1.273 .883 & $0,14 \%$ & 1.784 & $0,36 \%$ & $0,04 \%$ & 634 & $1973-198$ \\
\hline $\begin{array}{l}\text { Sinter e } \\
\text { ligas }\end{array}$ & 675.675 & $0,14 \%$ & 946 & $0,25 \%$ & $0,03 \%$ & 236 & 1988-199| \\
\hline $\begin{array}{l}\text { Rejeitos } \\
\text { pelotas }\end{array}$ & 75.600 & $0,19 \%$ & 144 & $0,36 \%$ & $0,36 \%$ & 511 & $1973-200$ \\
\hline Total & 34.203 .462 & $0,17 \%$ & 56.928 & Total so & lizável: & 2.032 & quilos \\
\hline
\end{tabular}


Com base nesses critérios, a Tabela 9 mostra que a solubilização máxima que pode ter ocorrido em Santana é da ordem de 2 toneladas de arsênio, distribuídos em 41 anos. A tabela também mostra que o arsênio contido nas 34.127.862 toneladas de produtos manganesíferos embarcados totalizou 56.784 toneladas (56.928 - 144).

\section{Arsênio na foz e no delta do rio Amazonas}

Recentemente o Laboratório de Química Analítica e Ambiental (LAQUANAM), da Universidade Federal do Pará, efetuou um detalhado trabalho de amostragem de águas do canal norte do rio Amazonas desde a frente de Santana até perto do mar, analisando-as para arsênio. O trabalho foi repetido no rio Pará, desde o canal de Breves até sua foz.

No Amazonas, foram encontrados valores variando de 0,03 a 0,16 $\mathrm{mg} / \mathrm{m}^{3}$ As e, no rio Pará, foram obtidos valores similares. Em seu relatório preliminar, o LAQUANAM sugeriu que as operações da ICOMI poderiam ser responsáveis por esses valores, inclusive no rio Pará (PEREIRA, 2000).

A Figura 11 apresenta os locais amostrados e os valores obtidos. Fica claro que os teores aumentam em direção ao mar, e os menores valores são observados exatamente em frente a Santana e a Macapá.

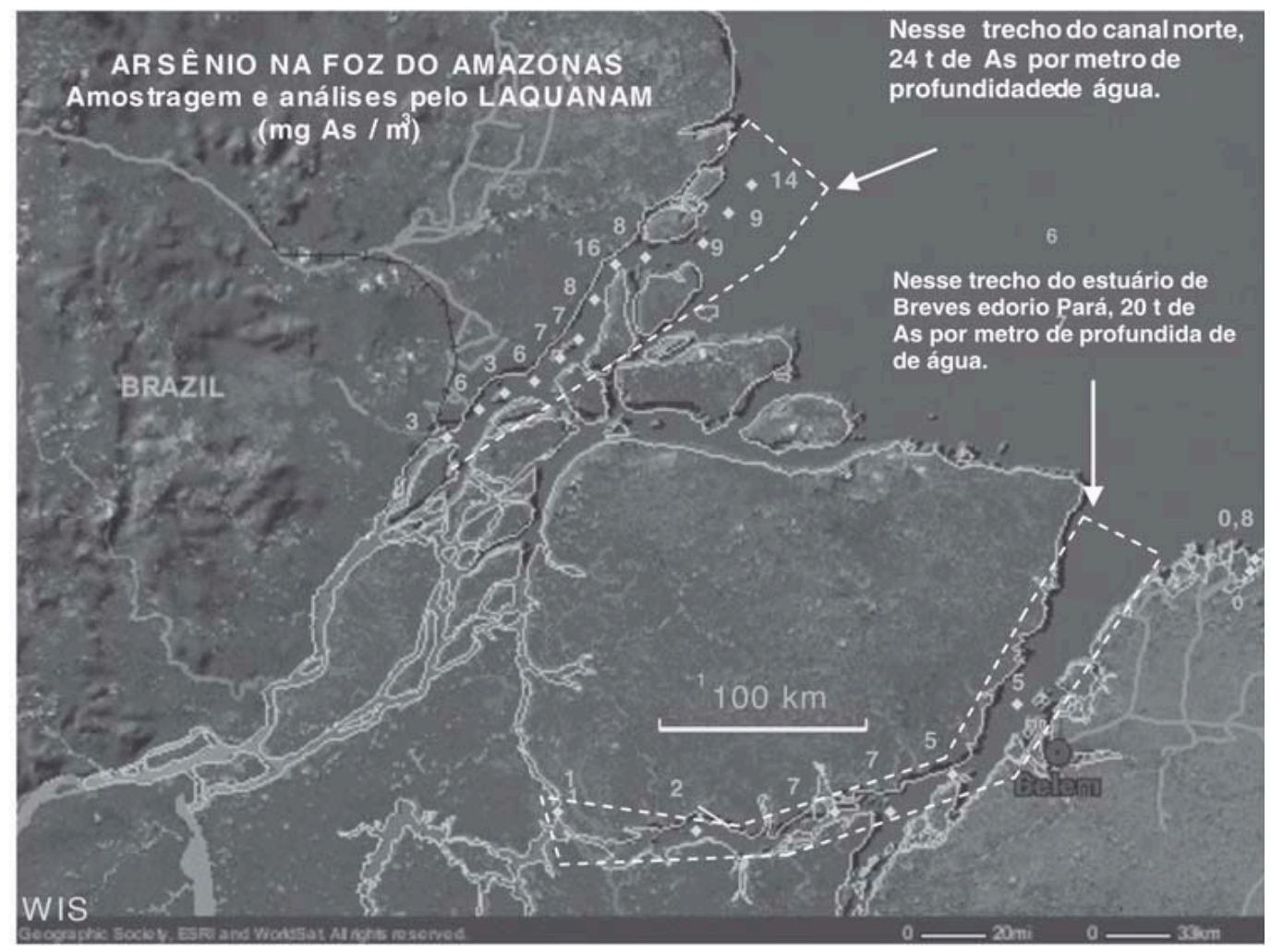

Figura 11: Pontos de amostragem de água do LAQUANAM, no canal norte do rio Amazonas e rio Pará. Os valores de arsênio estão expressos em $\mathrm{mg} / \mathrm{m}^{3}$. 
No mapa estão traçados dois polígonos, um sobre o canal norte do Amazonas e outro sobre o rio Pará. O polígono sobre o Amazonas cobre uma extensão de 200 x $15 \mathrm{~km}$, equivalente a 3 bilhões de metros quadrados. À concentração média de $8,01 \mathrm{mg} / \mathrm{m}^{3}$ de arsênio, obtida das amostras do LAQUANAM, essa área contém 24 toneladas de arsênio por metro de profundidade da coluna de água. O polígono sobre o rio Pará cobre aproximadamente 300 x 14 km, representando 4,2 bilhões de metros quadrados. À concentração média de 4,8 mg/m ${ }^{3}$ de arsênio, obtida das amostras do LAQUANAM, essa área contém 20 toneladas de arsênio por metro de profundidade da coluna de água.

Se for considerada toda a extensão da foz desses rios e do delta, o conteúdo de arsênio suplanta facilmente 100 toneladas por metro vertical da coluna de água.

\section{Arsênio na Bacia Amazônica}

Uma boa e importante fonte de informação sobre os valores de arsênio nos rios da Bacia Amazônica é o Projeto Hidrografia da Bacia Amazônica (HIBAM), um programa de pesquisa multinacional em execução pela Universidade de Brasília (UnB), pela Agência Nacional de Energia Elétrica (ANEEL), pelo Conselho Nacional de Desenvolvimento Científico e Tecnológico (CNPq) e pelo Institut Français de Recherche Scientifique pour le Développement en Cooperátion (IRD/ ORSTOM).

Os resultados mais recentes foram relatados por Seyler, do ORSTOM, e Boaventura, da UnB (SEYLER; BOAVENTURA, 2001). São resultados de amostragens dos rios da bacia em pontos de controle sedimentométrico do Departamento Nacional de Águas e Energia Elétrica (DNAEE), operados pela Agência Nacional de Energia Elétrica (ANEEL). Nesses pontos, onde são rotineiramente efetuadas medições de vazão, foram tomadas amostras para determinação dos teores de 16 elementos, inclusive arsênio, tanto na forma solubilizada como nos constituintes das partículas de sedimentos em transporte.

O arsênio ocorre nas formas solúvel e sólida. Como solúvel, aparece na forma iônica em sais e também como compostos orgânicos. Na forma sólida, aparece adsorvido ou absorvido em óxidos e hidróxidos de ferro e de manganês.

Os autores citados informam que a vazão do rio Amazonas em Óbidos é da ordem de $209.000 \mathrm{~m}^{3}$ por segundo e que anualmente o rio por ali transporta 600.000.000 t de sedimentos, 97\% dos quais provêm das drenagens originárias nos Andes, sendo 62\% pelo rio Solimões, proveniente dos Andes peruanos, e 35\% pelo rio Madeira, dos Andes bolivianos. Os demais 3\% de sedimentos provêm dos rios originários da plataforma cristalina. Essa é a razão pela qual os rios Solimões e Madeira 
são barrentos e os demais rios têm águas limpas. A Tabela 10, preparada com base nas tabelas 16.1 e 16.3 do trabalho de Seyler e Boaventura (2001), apresenta as datas de amostragem, a vazão nos pontos de amostragem, a massa sedimentar sólida em transporte, os teores de arsênio nos sedimentos e dissolvido na água e o quantitativo de arsênio contido nos sedimentos sendo transportados. A partir dessas medições, foram calculadas as massas de arsênio sendo transportadas, em toneladas por dia, e o teor total de arsênio nos pontos amostrados.

A Figura 12 mostra os teores de arsênio dissolvido, em mg/m (igual a ìg/L). Os maiores valores, com até $1,5 \mathrm{mg} / \mathrm{m}^{3}$, estão no rio Solimões, diminuindo para o leste, devido à diluição pelos rios provenientes do escudo cristalino. As cabeceiras do rio Madeira também apresentam resultados elevados, com 0,8 e $0,6 \mathrm{mg} / \mathrm{m}^{3}$. Os rios que drenam o cristalino apresentam valores da ordem de $0,1 \mathrm{mg} / \mathrm{m}^{3}$ ou menores.

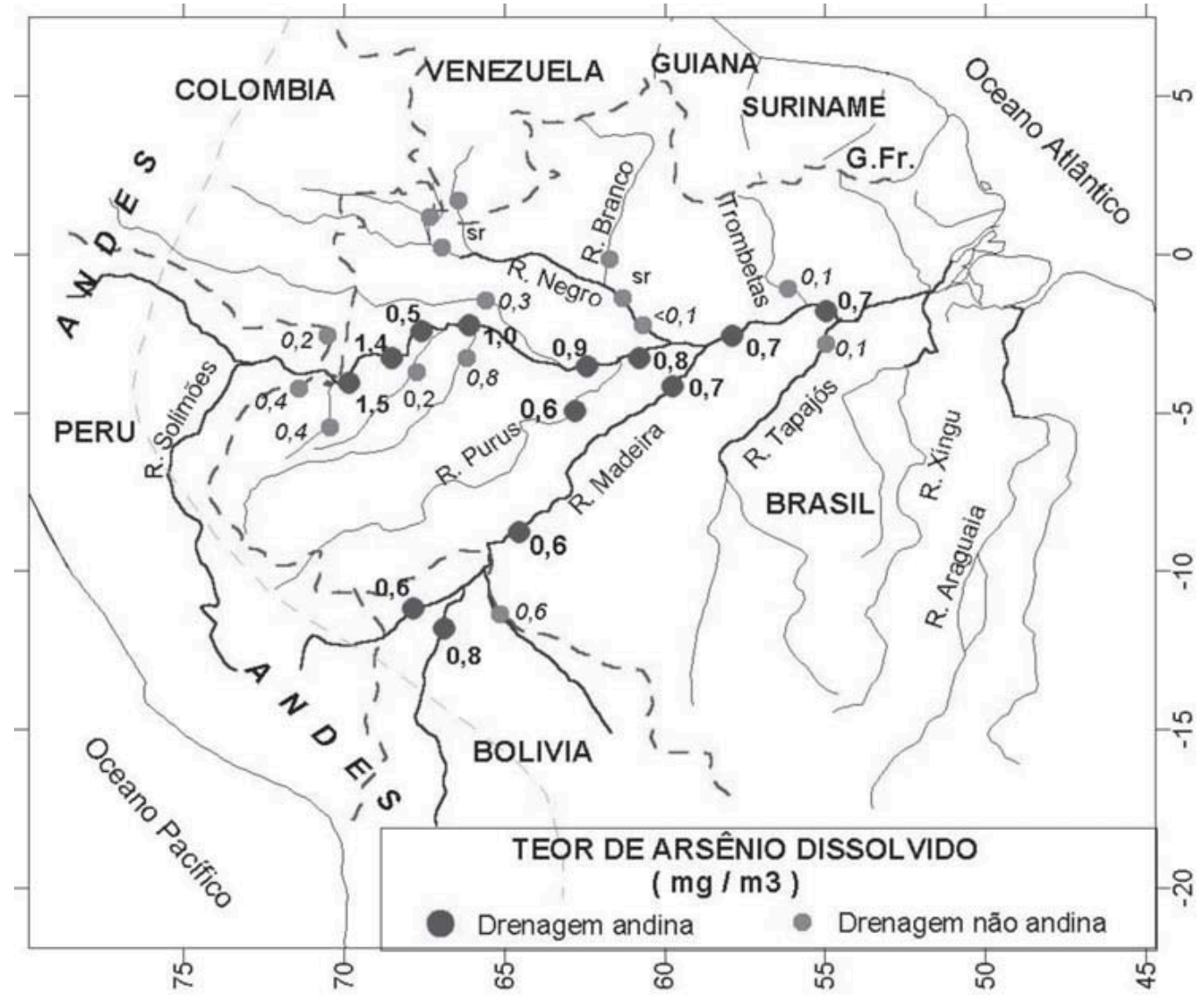

Figura 12: Teores de arsênio, em $\mathrm{mg} / \mathrm{m}^{3}$, dissolvido nas águas de rios da Bacia Amazônica.

Fonte: SEYLER; BOAVENTURA, 2001. 
Tabela 10: Conteúdo de arsênio nas águas de rios da Bacia Amazônica (*).

\begin{tabular}{|c|c|c|c|c|c|c|c|c|c|c|c|}
\hline \multicolumn{7}{|c|}{ Dados de Seyler e Boaventura } & \multicolumn{5}{|c|}{ Dados calculados } \\
\hline \multirow{2}{*}{ Rio } & \multirow{2}{*}{$\begin{array}{l}\text { Distância } \\
\text { do mar } \\
(\mathrm{km})\end{array}$} & \multicolumn{2}{|c|}{ Vazão medida } & \multirow{2}{*}{$\begin{array}{l}\text { Teor de As } \\
\text { em } \\
\text { solução } \\
(\mathrm{mg} / \mathrm{m} 3)\end{array}$} & \multirow{2}{*}{$\begin{array}{l}\text { Sedimentos } \\
\text { em } \\
\text { suspensão } \\
(\mathrm{g} / \mathrm{m} 3)\end{array}$} & \multirow{2}{*}{$\begin{array}{l}\text { Teor de As } \\
\text { nos } \\
\text { sedimentos } \\
(\mathrm{g} / \mathrm{t})\end{array}$} & \multirow{2}{*}{$\begin{array}{c}\text { Teor As } \\
\text { devido aos } \\
\text { sedimentos } \\
(\mathrm{mg} / \mathrm{m} 3)\end{array}$} & \multirow{2}{*}{$\begin{array}{l}\text { Transporte } \\
\text { de As em } \\
\text { sedimentos } \\
\text { (t/dia) }\end{array}$} & \multirow{2}{*}{$\begin{array}{c}\text { Transporte } \\
\text { de As em } \\
\text { solução } \\
\text { (t/dia) }\end{array}$} & \multirow{2}{*}{$\begin{array}{c}\text { Transporte } \\
\text { total de As } \\
\text { (t/dia) }\end{array}$} & \multirow{2}{*}{$\begin{array}{c}\text { Teor total } \\
\text { de As na } \\
\text { vazão } \\
(\mathrm{mg} / \mathrm{m} 3)\end{array}$} \\
\hline & & $\begin{array}{c}\text { Vazão } \\
\text { (m3/seg) }\end{array}$ & Data & & & & & & & & \\
\hline Solimões & 2.500 & 20.115 & 26/out/95 & 1,53 & 166,5 & 14,5 & 2,41 & 0,42 & 0,27 & 0,69 & 3,94 \\
\hline Javari & & 1.565 & 27/out/95 & 0,36 & 127,6 & 5,8 & 0,74 & 0,01 & 0 & 0,01 & 1,1 \\
\hline Itaquai & & 793 & 27/out/95 & 0,44 & 148,3 & 7,9 & 1,17 & 0,01 & 0 & 0,01 & 1,61 \\
\hline Solimões & 2.200 & 24.251 & 28/out/95 & 1,38 & 74,5 & 15,7 & 1,17 & 0,25 & 0,29 & 0,53 & 2,55 \\
\hline Içá & & 5.354 & 31/out/95 & 0,15 & 41,4 & 3,5 & 0,14 & 0,01 & 0,01 & 0,01 & 0,29 \\
\hline Solimões & & 32.539 & 29/out/95 & 0,49 & 46 & 9,7 & 0,45 & 0,13 & 0,14 & 0,26 & 0,94 \\
\hline Jutai & & 1.143 & 3/nov/95 & 0,15 & 13,5 & 3,4 & 0,05 & 0 & 0 & 0 & 0,2 \\
\hline Solimões & 1.900 & 34.333 & 3/nov/95 & 1,01 & 60,9 & 10 & 0,61 & 0,18 & 0,3 & 0,48 & 1,62 \\
\hline Juruá & & 1.045 & $4 /$ nov/95 & 0,85 & 56,3 & 10,1 & 0,57 & 0,01 & 0,01 & 0,01 & 1,42 \\
\hline Japurá & & 10.264 & 4/nov/95 & 0,33 & 28,5 & 13,6 & 0,39 & 0,03 & 0,03 & 0,06 & 0,72 \\
\hline Solimões & 1.380 & 46.847 & $7 /$ nov/95 & 0,88 & 63,7 & 3 & 0,19 & 0,08 & 0,36 & 0,43 & 1,07 \\
\hline Purus & & 2.534 & 9/nov/95 & 0,55 & 38,6 & 3,1 & 0,12 & 0 & 0,01 & 0,01 & 0,67 \\
\hline Solimões & 1.200 & 52.477 & $10 /$ nov/95 & 0,77 & 127,1 & 2,8 & 0,36 & 0,16 & 0,35 & 0,51 & 1,13 \\
\hline Negro & 1.250 & 64.680 & 12/jul/96 & 0,05 & 8,9 & 7,9 & 0,07 & 0,04 & 0,03 & 0,07 & 0,12 \\
\hline Beni & & 2.856 & 1/abr/94 & 0,83 & 937 & 19,9 & 18,65 & 0,46 & 0,02 & 0,48 & 19,48 \\
\hline Madre Diós & & 5.092 & 2/abr/94 & 0,61 & 424 & 10 & 4,24 & 0,19 & 0,03 & 0,21 & 4,85 \\
\hline Mamoré & & 8.391 & 3/abr/94 & 0,61 & 409 & 11,9 & 4,87 & 0,35 & 0,04 & 0,4 & 5,48 \\
\hline Madeira & 1.950 & 29.000 & $12 / a b r / 98$ & 0,59 & 302 & sr & sr & 0 & 0,15 & 0,15 & 0,59 \\
\hline Madeira & 1.200 & 5.132 & $15 /$ nov/95 & 0,69 & 21,3 & 2,7 & 0,06 & 0 & 0,03 & 0,03 & 0,75 \\
\hline Amazonas & 1.000 & 75.017 & $15 /$ nov/95 & 0,73 & 46,1 & 81,9 & 3,78 & 2,45 & 0,47 & 2,92 & 4,51 \\
\hline Trombetas & & 1.258 & 16/nov/95 & 0,12 & 14,8 & 17,1 & 0,25 & 0 & 0 & 0 & 0,37 \\
\hline Tapajós & & 6.027 & $18 /$ nov/95 & 0,11 & 3,5 & 17,7 & 0,06 & 0 & 0,01 & 0,01 & 0,17 \\
\hline Amazonas & 650 & 81.090 & $17 /$ nov/95 & 0,68 & 44,2 & 2,8 & 0,12 & 0,09 & 0,48 & 0,56 & 0,8 \\
\hline
\end{tabular}

(*) A Tabela 10 foi elaborada com base em medições de vazão e de amostragens e em análises de água e de sólidos em suspensão apresentadas por P. T. Seyler e G. R. Boaventura (2001, p. 307-327). 
A Figura 13 mostra os teores de arsênio correspondentes aos sedimentos transportados. Esses valores foram obtidos a partir dos dados de vazão, da massa de sedimentos e das análises desses sedimentos. Os maiores valores foram observados perto dos Andes, com 2,4 mg/m no rio Madeira e $18,6 \mathrm{mg} / \mathrm{m}^{3}$ no rio Solimões. Os teores decrescem para o leste, devido à diluição com águas dos rios do cristalino.

As Figuras 12 e 13 indicam que, ao passar por Óbidos, o rio Amazonas tem mais de $0,8 \mathrm{mg} / \mathrm{m}^{3}$ de arsênio, sendo $0,7 \mathrm{mg} / \mathrm{m}$ dissolvido e $0,1 \mathrm{mg} / \mathrm{m}^{3}$ ou mais devido aos sedimentos em suspensão. As variações observadas podem ser devidas a mudanças sazonais na bacia e ao fato de que os sedimentos são amiúde depositados nas várzeas e a seguir erodidos e colocados novamente em transporte.

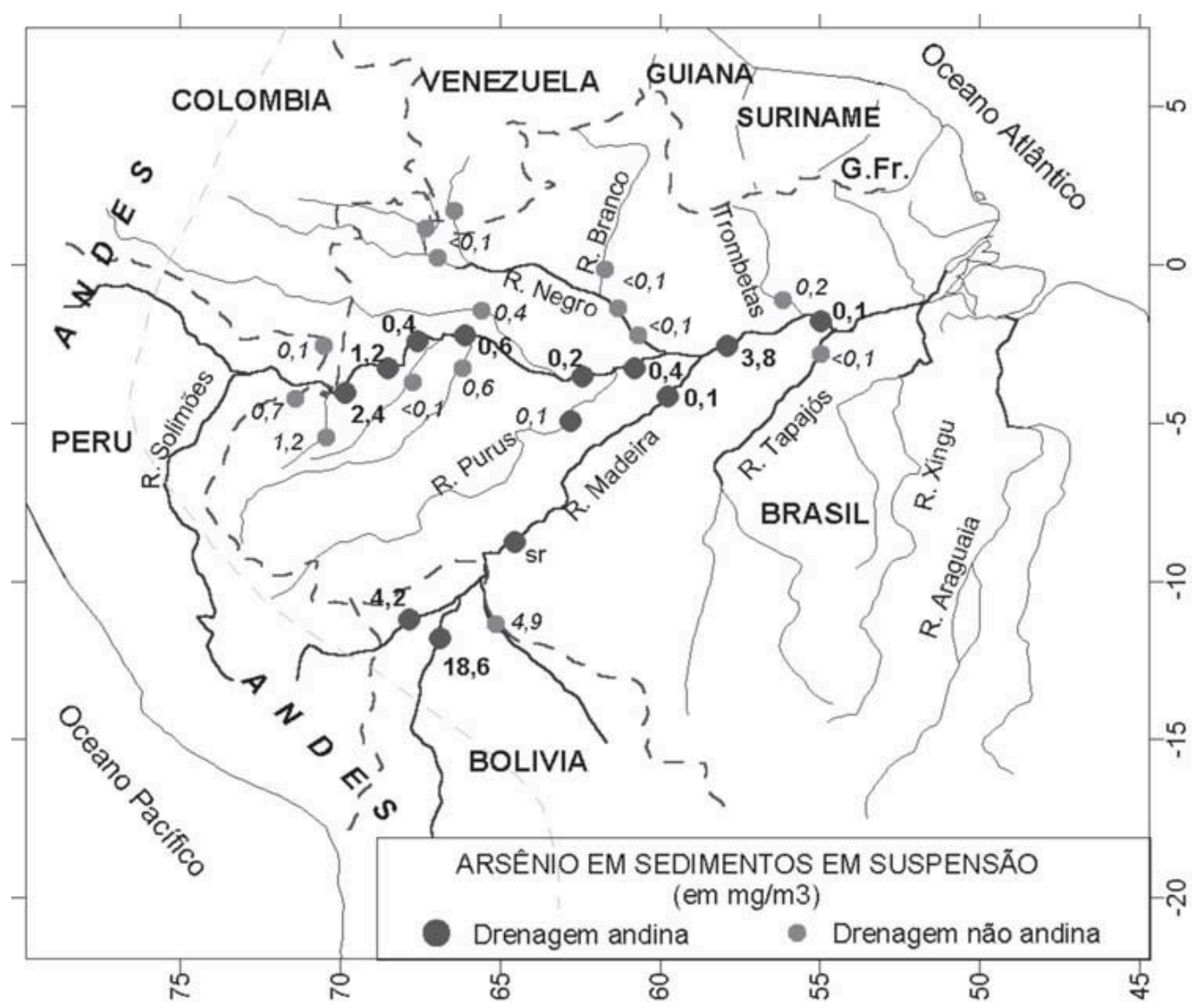

Figura 13: Teores de arsênio, em mg/m³ $\mathrm{m}^{3}$ transportados nos sedimentos em suspensão nos rios da Bacia Amazônica. Fonte: SEYLER; BOAVENTURA, 2001.

Conhecendo-se os teores e as vazões, é possível determinar a quantidade de arsênio, em toneladas por dia, transportada diariamente pelos pontos de amostragem. A Figura 11 apresenta os resultados obtidos. Os maiores valores estão nos rios com águas provenientes dos 
Andes, tendo sido obtidos valores de 0,26 a 0,69 t/dia no rio Solimões, de 0,48 a 0,15 t/dia no rio Madeira e de 0,56 a 2,92 t/dia no rio Amazonas, estas últimas respectivamente em Óbidos e Itacoatiara.

Os números representam ocasiões específicas de fluxo do rio e indicam a variabilidade que ocorre. A vazão de 0,56 toneladas diárias de arsênio, conforme a amostra tomada em Óbidos, representaria 200 toneladas anuais de arsênio transportadas pelo rio em direção ao mar, enquanto a vazão de 2,92 toneladas diárias em Oriximiná representaria 1.065 toneladas anuais de arsênio. O valor real pode estar entre esses montantes.

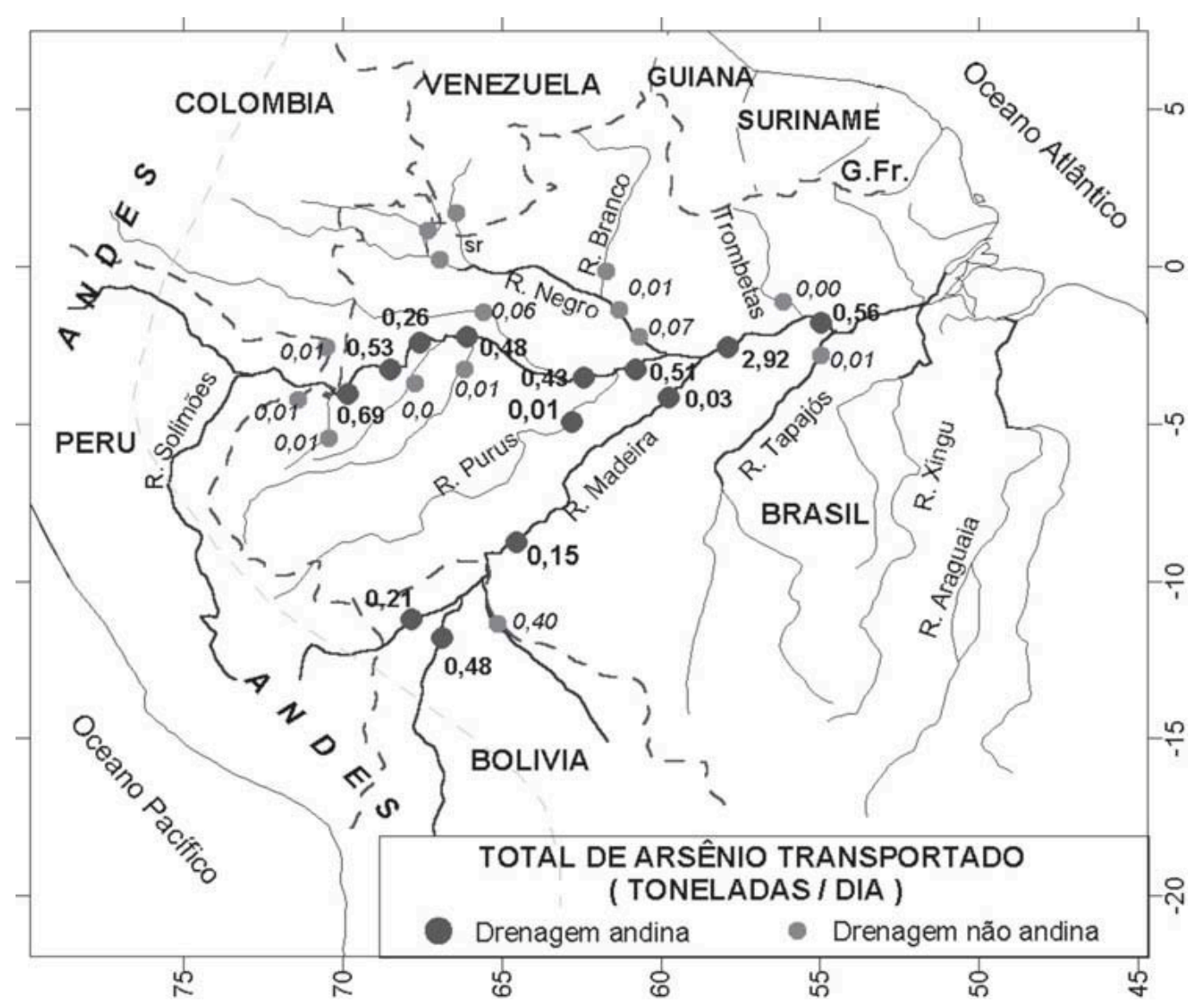

Figura 14: Arsênio transportado pelos rios da Bacia Amazônica, em toneladas por dia.

Fonte: SEYLER; BOAVENTURA, 2001.

Ferro e arsênio na plataforma sedimentar marinha

Os sedimentos depositados na plataforma marinha no delta do Amazonas têm sido muito estudados, por motivos científicos e também tendo em vista a possibilidade de ocorrência de petróleo. As observações apresentadas a seguir foram obtidas com base em amostras coletadas em seções de sondagem efetuadas na plataforma. 
McDaniel, McLennan e Hanson (1997, p. 169, tradução nossa) demonstraram, com estudos comparativos de isótopos de neodímio e de chumbo, que "[...] as lamas depositadas no Delta Amazônico derivam predominantemente das montanhas andinas. Além disso, [...] elas não foram afetadas pelo intenso intemperismo que existe hoje na Bacia Amazônica". A essa conclusão havia chegado Gibbs (1967), com estudos dos sedimentos do rio Amazonas. Nanayama (1997) verificou que na plataforma há também minerais provenientes do escudo brasileiro. De modo geral, os sedimentos são constituídos de argilas, quartzo, alguns silicatos e óxidos e hidróxidos de ferro.
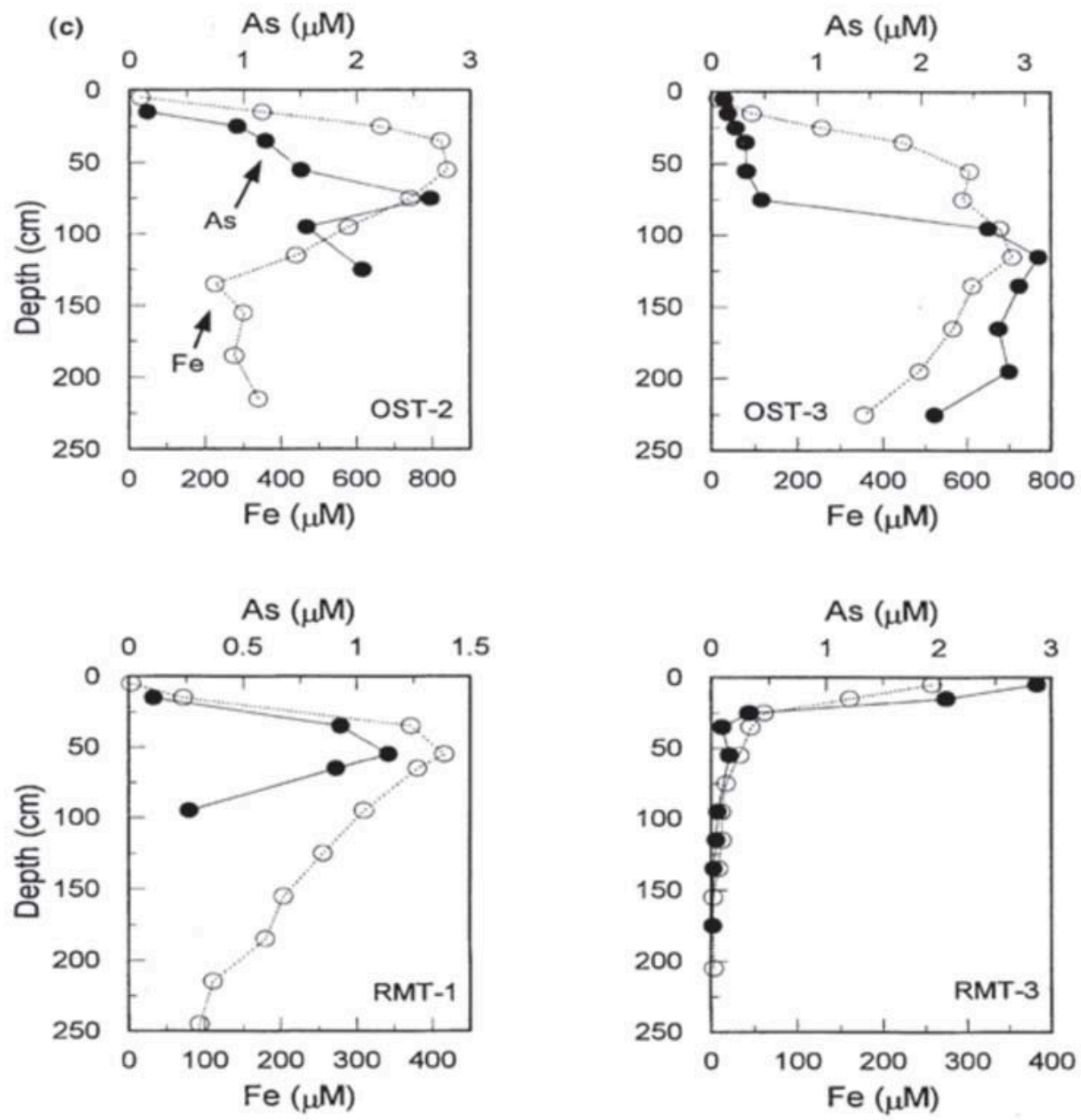

Figura 15: Análise de água dos poros de sedimentos da borda externa da plataforma marinha, na foz do rio Amazonas*.

*Resultados obtidos por sondagens realizadas pelo Multidisciplinary Amazon Shelf Sediment Study (SULLIVAN; ALLER, 1996). O aumento dos teores de arsênio e de ferro em solução à profundidade de 0,25 a 1,5 m deve-se à recristalização dos oxihidróxidos de ferro em sulfetos e carbonatos de ferro. 
Burns (1997) relata a presença de uma associação de minerais secundários de ferro, a cerca de um metro de profundidade e de espessura centimétrica a decimétrica, formando um nível lateralmente contínuo na plataforma marinha. Nesse nível predominam sulfetos, fosfatos e carbonatos de ferro. Verificou que esses minerais formam-se no próprio local onde se encontram, a partir de dissoluções e recristalizações, sob condições quimicamente redutoras, ou desoxidantes, dos hidróxidos, óxidos e sulfatos de ferro trazidos pelo rio e depositados à superfície dos sedimentos.

Sullivan e Aller (1996) verificaram que as recristalizações que deram origem a esses sulfetos, fosfatos e carbonatos de ferro causaram a liberação do arsênio que estava contido nos óxidos e hidróxidos de ferro e que o arsênio liberto encontra-se livre, dissolvido na água que preenche os poros dos sedimentos, aparecendo com teores máximos a profundidades de 0,25 a 1,5 metros. Informam:

a concentração máxima observada de arsênio é de uma ordem de magnitude maior que os níveis encontrados na maioria dos outros ambientes marinhos e concentrações elevadas de arsênio estendem-se por vários metros abaixo da superfície dos sedimentos. [...] Esses padrões refletem intensas reduções químicas vinculadas ao ferro, de forma que o arsênio, que na superfície dos sedimentos ocorre na forma oxidada, nos oxihidróxidos de ferro, é reduzido e liberado quando soterrado pela sedimentação. A difusão para cima do arsênio possivelmente o libera para a coluna de água ou permite sua reabsorção na zona superior dos sedimentos (SULLIVAN; ALLER, 1996, tradução nossa).

Dessa forma, os teores de arsênio nas águas da plataforma sedimentar marinha podem ser maiores que no rio Amazonas, com o excedente provindo dos sedimentos revolvidos por correntes marinhas ou por ondas fortes.

Uso de manganês para a retirada de arsênio de águas ricas em arsênio

A afinidade química entre o manganês e a arsênio é tão boa, ou até melhor, que a afinidade do arsênio por ferro. O minério óxido da Serra do Navio é um bom exemplo disso. Conforme foi comprovado pelos ensaios de solubilização ora relatados, é muito difícil, nas condições atmosféricas naturais, liberar o arsênio absorvido nas estruturas dos óxidos e hidróxidos de manganês. Para tal, seria necessário submeter os minerais a ambientes fortemente redutores, isto é, liberadores de oxigênio. 
A afinidade entre o manganês e o arsênio tem sido usada técnica e comercialmente, na produção de equipamentos para a remoção de arsênio da água, com a finalidade de torná-la potável. Os mais modernos equipamentos, entre os quais os produzidos pela Pump House, Tonka Equip. Co. e Westech Inc. (CLACK CORP, 2002; PUMP HOUSE, 2002; SUBRAMANIAN, K. S. et al., 1997; TONKA EQUIP. CO., 2002; VIRARAGHAVAN; SUBRAMANIAN; ARULDOSS, 1999; WESTECH INC. GREENSAND FILTERS, 2002), empregam filtros de greensand, que nada mais são que areias silicáticas finas, sobre as quais se coloca permanganato de potássio. Na filtragem, à medida que a água passa pela areia fina, o permanganato oxida-se e forma óxidos e hidróxidos, absorvendo e retirando arsênio do líquido. Quando o filtro perde eficiência, removem-se os óxidos de manganês neoformados e colocase mais permanganato. As referências citadas e outras estão disponíveis na Internet. 


\section{REFERÊNCIAS}

AMPLA Engenharia. Relatório de monitoramento ambiental, região de Santana, Amapá. abr. 2002.

BURNS, S. J. Early diagenesis in Amazon fan sediments. In: FLOOD, R. D. et al. (Ed.). Proceedings of the Ocean Drilling Program, Scientific Results. v. 155. Chapter 30, p. 497-504. 1997.

CLACK CORP. Manganese greensand. Disponível em: <http:// www.clackcorp.com/water/pdf/manggreens.pdf $>$. Acesso em 12 set. 2002.

FUNDAÇÃO COPPETEC. Parecer sobre a periculosidade dos rejeitos de mineração de manganês da pilha de rejeitos da área industrial, Santana, Amapá. 2001.

GIBBS, R. J. The geochemistry of the Amazon River system: Part I. The factors that control the salinity and the composition and concentration of the suspended solids. The Geological Society of America Bulletin. v. 78, n. 10, p. 1203-1232, out. 1967.

HIDRO AMBIENTE PROJETOS, CONSULTORIA E SERVIÇOS S/C. Dimensionamento dos depósitos estocados na área industrial da ICOMI, Santana-AP. ago. 1999.

INSTITUTO EVANDRO CHAGAS. Resultados parciais do estudo de saúde humana realizado na comunidade do Elesbão, Santana, Amapá. Belém, dez. 2001.

INSTITUTO EVANDRO CHAGAS. Resultado da investigação sobre exposição ao arsênio na comunidade do Elesbão, município de Santana, Amapá. Belém, abr. 2002.

JP ENGENHARIA. Monitoramento ambiental no interior e vizinhanças da área industrial ICOMI, Santana-AP (março 2001). Relatório 70-276Ejpe-1800. 2001.

\section{JAAKKO PÖYRY ENGENHARIA LTDA. Anteprojeto de disposição final dos resíduos da usina de pelotização/sinterização estocados na área industrial da ICOMI, Santana-AP. 1998.}




\section{LAKEFIELD-GEOSOL. Certificado de análise, solubilização e lixiviação.} 2001.

McDANIEL, D. K.; McLENNAN, S. M.; HANSON, G. N. Provenance of Amazon fan muds: constraints from $\mathrm{Nd}$ and $\mathrm{Pb}$ isotopes. In: FLOOD, R. D. et al. (Ed.). Proceedings of the Ocean Drilling Program, Scientific Results, 1997, v. 155. Chapter 8, p. 169-176. Disponível em: <http:// www-odp.tamu.edu/publications/155_SR/ABSTRACT/8.HTM>. Acesso em: 5 out. 2002.

NANAYAMA, F. An electron microprobe study of the Amazon fan. In: FLOOD, R. D. et al. (Ed.). Proceedings of the Ocean Drilling Program, Scientific Results. 1997, v. 155. Chapter 7, p. 147-168.

PEREIRA, S. F. P. Avaliação da contaminação por metais pesados no delta do rio Amazonas: relatório parcial. Belém: Universidade Federal do Pará, LAQUANAM. 2000

PUMP HOUSE. Manganese greensand filtration. Disponível em: < http:/ /www.pumphousebc.com/ maganese_greensand_filtration.html > . Acesso em: 15 out. 2002.

SEYLER, P. T.; BOAVENTURA, G. R. Trace Elements in the Mainstem Amazon River. In: McCLAIN, M. E.; VICTORIA, R. L.; RICHEY, J. E. (Ed.). The Biogeochemistry of the Amazon Basin. New York: Oxford Press, 2001. p. 307-327.

SUBRAMANIAN, K. S. et al. Manganese greensand for removal of arsenic in drinking water. Water Quality Research Journal of Canada. v. 32, n. 2, p. 551-561, 1997.

SULLIVAN, K. A.; ALLER, R. C. Diagenetic cycling of arsenic in Amazon shelf sediments. Geochimica et Cosmochimica Acta. v. 60, n. 9, p. 14651477, maio 1996.

TONKA EQUIP. CO. Arsenic removal from potable water. Disponível em: <http://www.tonkawater.com/whatsnew/article.cfm?AID =10>. Acesso em: 15 out 2002. 
Wilson Scarpelli

VIRARAGHAVAN, T.; SUBRAMANIAN, K. S.; ARULDOSS, J. A. Arsenic in drinking water-problems and solutions. Water Science and Technology. v. 40, n. 2, p. 69-76, 1999.

WESTECH INC. GREENSAND FILTERS. Disponível em: < http:// www.westech-inc.com/greensand.html >. Acesso em: 20 nov. 2002.

WORLD HEALTH ORGANIZATION. Arsenic and Arsenic Compounds. 2nd edition. Geneva, 2001 (Environmental Health Criteria Series, No 224). 